\title{
Collecting Agent-Mineral Interactions in the Reverse Flotation of Iron Ore: A Brief Review
}

\author{
Guixia Fan ${ }^{1}$, Liguang Wang ${ }^{2}$, Yijun $\mathrm{Cao}^{1}$ and Chao $\mathrm{Li}^{3, *}$ \\ 1 School of Chemical Engineering, Zhengzhou University, Zhengzhou 450001, China; cumtfgx@126.com (G.F.); \\ yijuncao@126.com (Y.C.) \\ 2 School of Chemical Engineering, The University of Queensland, Brisbane, Queensland 4072, Australia; \\ liguang.wang@uq.edu.au \\ 3 Henan Province Industrial Technology Research Institute of Resources and Materials, Zhengzhou University, \\ Zhengzhou 450001, China \\ * Correspondence: c.li@zzu.edu.cn
}

Received: 28 May 2020; Accepted: 28 July 2020; Published: 30 July 2020

\begin{abstract}
Froth flotation has been widely used in upgrading iron ores. Iron ore flotation can be performed in two technical routes: direct flotation of iron oxides and reverse flotation of gangue minerals with depression of iron oxides. Nowadays, reverse flotation is the most commonly used route in iron ore flotation. This review is focused on the reverse flotation of iron ores, consisting of reverse cationic flotation and reverse anionic flotation. It covers different types of collecting agents used in reverse iron ore flotation, the surface characteristics of minerals commonly present in iron ores (e.g., iron oxides, quartz, alumina-bearing minerals, phosphorus-bearing minerals, iron-bearing carbonates, and iron-bearing silicates), and the adsorption mechanisms of the collecting agents at the mineral surface. The implications of collecting agent-mineral interactions for improving iron ore flotation are discussed.
\end{abstract}

Keywords: iron ore; reverse flotation; cationic collector; anionic collector; surface adsorption

\section{Introduction}

Steel is an indispensable material for the construction industry, shipbuilding, railway construction, motor vehicle manufacture, bridge building, machinery manufacture, and many other engineering applications. Steel is made mainly from iron, which is one of the most abundant elements on Earth. Iron is extracted primarily from iron ores. The iron ores mainly include oxides and hydroxides such as magnetite $\left[\mathrm{Fe}_{3} \mathrm{O}_{4}\right]$, hematite $\left[\mathrm{Fe}_{2} \mathrm{O}_{3}\right]$, goethite $[\mathrm{FeO}(\mathrm{OH})]$, and limonite $\left[\mathrm{FeO}(\mathrm{OH}) \cdot \mathrm{nH}_{2} \mathrm{O}\right][1]$. The primary gangue mineral in iron ores is quartz. In addition to quartz, iron-bearing silicates (e.g., amphiboles and pyroxenes), carbonates, clays (e.g., kaolinite), and gibbsite are also commonly present in iron ores [1,2]. Iron ore beneficiation aims to eliminate the harmful elements in iron ore concentrate, which could impose a detrimental effect on ironmaking. Table 1 summarizes the allowed contents of the harmful elements in the iron ore concentrate (in China) and their effects on ironmaking/steelmaking. 
Table 1. The allowed content of the harmful elements in iron ore concentrate [3] and their detrimental effects on ironmaking.

\begin{tabular}{cccc}
\hline Elements & Magnetite Concentrate & Hematite Concentrate & $\begin{array}{c}\text { Detrimental Effect on the Mechanical } \\
\text { Properties of Iron/Steel }\end{array}$ \\
\hline $\mathrm{Si} \mathrm{( \% )}$ & $\leq 4.2$ & $\leq 5.6$ & Decreased toughness and weldability [4] \\
\hline $\mathrm{S}(\%)$ & $\leq 0.50$ & $\leq 0.30$ & $\begin{array}{c}\text { Increased brittleness of steel and decreased } \\
\text { weldability and corrosion resistance [5] }\end{array}$ \\
\hline $\mathrm{P}(\%)$ & $\leq 0.10$ & $\leq 0.10$ & $\begin{array}{r}\text { Increased hardness and brittleness and } \\
\text { decreased ductility [6] }\end{array}$ \\
\hline $\mathrm{Al}(\%)$ & $\leq 1.1$ & $\leq 0.8$ & Decreased creep resistance [7] \\
\hline
\end{tabular}

The amount of high grade and easy-to-process iron ores are in continual decline and beneficiation of iron ores is in increasing demand. A challenge is to upgrade the low-grade iron ores with complex mineralogy and fine grain size, which require the beneficiation to be carried out at fine or ultrafine size fractions [8]. A versatile method of beneficiation of fine and ultrafine particles is froth flotation. In the flotation of iron ores, the difference in flotation rates between iron oxides and gangue minerals needs to be enlarged, which can be achieved by changing the surface hydrophobicity of certain minerals using various reagents, such as $\mathrm{pH}$ modifiers, depressants, activators, and collectors.

Since the early stage of technology development for iron ore flotation in the 1930s, the following two technical routes of iron ore flotation have been developed: (i) direct flotation of iron oxides and (ii) reverse flotation of gangue minerals by depressing iron oxides. The route of reverse flotation is currently in widespread use in iron ore flotation practice. The majority of studies on reverse flotation of iron ore focused on reagents and reagent scheme [9-13]. The reverse flotation route can be classified into reverse cationic flotation and reverse anionic flotation, based on the collector type. The reverse anionic flotation (flotation of gangue minerals using anionic collectors that mainly include fatty acids) was developed in the early 1960s [14]. At present, reverse anionic flotation is mainly applied in China to upgrade iron ores [15-17]. The most popular flotation route in the iron ore industry worldwide is reverse cationic flotation $[1,17,18]$. The cationic collectors have evolved from fatty amines in the early industrial applications to ether amines with relatively high solubility in water at the present [9]. Apart from using a cationic or an anionic collector alone, the use of reagent mixtures has been increasingly popular in the reverse iron ore flotation practice. The mixtures can be (i) anionic/anionic collectors, (ii) anionic/cationic collectors, or (iii) ionic/non-ionic combinations [10]. The presence of the co-surfactants in solution can enhance the adsorption of the collectors at the solid/water interface and improve the mineral hydrophobicity [11-13].

The performance of the reverse flotation of iron ores is largely governed by the interactions between collectors and minerals, which are complex. A common task in the reverse flotation of iron ores is to separate quartz from iron oxides as quartz is often the major gangue mineral in iron ores. In some iron ores, removal of non-quartz gangue minerals is also essential, which has been the subject of several studies [16,19-23]. These non-quartz gangue minerals include alumina-containing minerals, phosphorus-containing minerals, iron-bearing carbonates, and iron-bearing silicates. The presence of these gangue minerals not only complicates the flotation system, but also imposes a detrimental effect on downstream steel-making processes. The surface properties of these gangues minerals are different from that of quartz, so they are often treated separately in the flotation process.

To date, several review papers $[1,9,10,14,18,24,25]$ either discuss the collector-mineral interactions in a single flotation route or cover the collectors used in different iron ore flotation routes, but neglect the fundamental interactions between collectors and minerals. There are still no reviews dedicated to the interactions between collectors and minerals in different iron ore flotation routes. In particular, the present work reviewed the interactions between quartz to non-quartz gangue minerals and collectors, aiming at facilitating the process of complex iron ores. It is expected that a fundamental understanding of the interactions between collectors and mineral surfaces will contribute to the design of appropriate flotation collectors and collector regimes for iron ore beneficiation. As only reverse cationic and anionic 
flotation routes are currently used in industry, the present work focuses on reviewing the fundamental collector-mineral interactions in these two routes.

\section{Collectors for Quartz}

As quartz is the main gangue mineral in iron ores, this section focuses on the interactions between collectors and quartz in aqueous solution. The interactions between collectors and non-quartz gangues will be discussed in Section 3.

\subsection{Anionic Collectors}

Fatty acids are widely used as a collector in the reverse anionic flotation of iron ores. The most popular anionic collectors used in iron ore flotation practice are oleic acid and its soaps $[16,26]$. The oleate in aqueous solution forms different species and which species dominate is dependent on $\mathrm{pH}$. Table 2 summarizes the equilibrium constants for oleate aqueous species at atotal ionic concentration of $1 \times 10^{-2} \mathrm{~mol} / \mathrm{L}$. Figure 1 shows the species distribution diagram of oleate as a function of $\mathrm{pH}$. The oleate is insoluble in acidic $\mathrm{pH}$ region, existing in the form of oleic acid droplet, emulsion, and insoluble film [27]. The solubility of the oleate ions increases as the $\mathrm{pH}$ is raised to alkaline. At a $\mathrm{pH}$ value above 11 , the oleate species exist mainly in the form of oleate ion $\left(\mathrm{RCOO}^{-}\right)$and oleate dimer $\left((\mathrm{RCOO}){ }_{2}{ }^{2-}\right)$. Oleate ions are the functional species that can interact with the quartz surface activated by polyvalent metal cations (the details are discussed below). This is why reverse anionic flotation of iron ore using oleic acid or its soaps is usually performed in a strongly alkaline environment (i.e., above pH 11). Fuerstenau and Cummins [28] concluded that, when oleate was used as collector, the suitable $\mathrm{pH}$ value was between 11 and 12 in the flotation of quartz.

Table 2. Equilibrium constants for oleate species in aqueous solution [29] (total ionic concentration $=1 \times$ $\left.10^{-2} \mathrm{~mol} / \mathrm{L}\right)$.

\begin{tabular}{cc}
\hline Equilibria & Constants \\
\hline $\mathrm{HOl} \rightleftharpoons \mathrm{H}^{+}+\mathrm{Ol}^{-}$ & $\mathrm{pK}_{a}^{\prime}=4.95$ \\
$\mathrm{HOl}_{1} \rightleftharpoons \mathrm{H}^{+}+\mathrm{Ol}^{-}$ & $\mathrm{pK}_{s p}^{\prime}=12.55$ \\
$2 \mathrm{Ol}^{-} \rightleftharpoons \mathrm{Ol}_{2}^{2-}$ & $\operatorname{logK} K_{D}^{\prime}=4.00$ \\
$\mathrm{HOl}+\mathrm{Ol}^{-} \rightleftharpoons \mathrm{HOl}_{2}^{-}$ & $\log \mathrm{K}_{A D}=4.75$ \\
$\mathrm{NaHOl}_{2(1)} \rightleftharpoons \mathrm{Na}^{+}+\mathrm{H}^{+}+2 \mathrm{Ol}^{-}$ & $\mathrm{pK}_{s p}^{\prime}=19.00$ \\
\hline
\end{tabular}

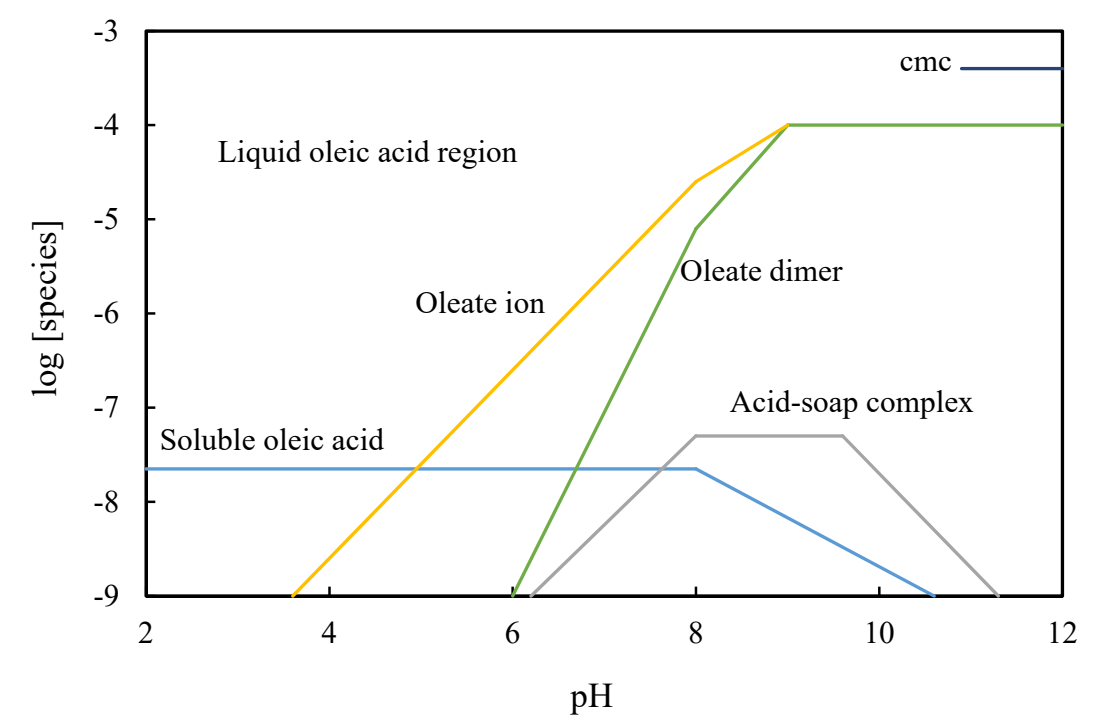

Figure 1. Species distribution diagram of oleate as a function of $\mathrm{pH}\left(\right.$ total concentration $\left.=1 \times 10^{-2} \mathrm{~mol} / \mathrm{L}\right)$ (after [29]). 
At pHs 11-12, the oleate ions cannot, however, directly adsorb onto the quartz surface. At this $\mathrm{pH}$ range, the quartz surface is negatively charged [30], so the adsorption of oleate ions on the quartz surface would be resisted by the electrostatic repulsion. The quartz needs to be firstly activated by adsorption of multivalent ions to reverse its surface charge from negative to positive. The most prevailing cation used for this purpose is $\mathrm{Ca}^{2+}$ (often sourced from lime). The species of calcium ions existing in solution are also $\mathrm{pH}$-dependent [31,32]. Figure 2 shows that, at the $\mathrm{pH}$ range of 11-12, the dominant species of calcium existing in the solution are $\mathrm{Ca}^{2+}$ and $\mathrm{Ca}(\mathrm{OH})^{+}$. It has been reported that the $\mathrm{Ca}(\mathrm{OH})^{+}$is the species that can adsorb onto the negatively charged quartz surfaces, forming $\mathrm{SiO}-\mathrm{Ca}(\mathrm{OH})$ [31].

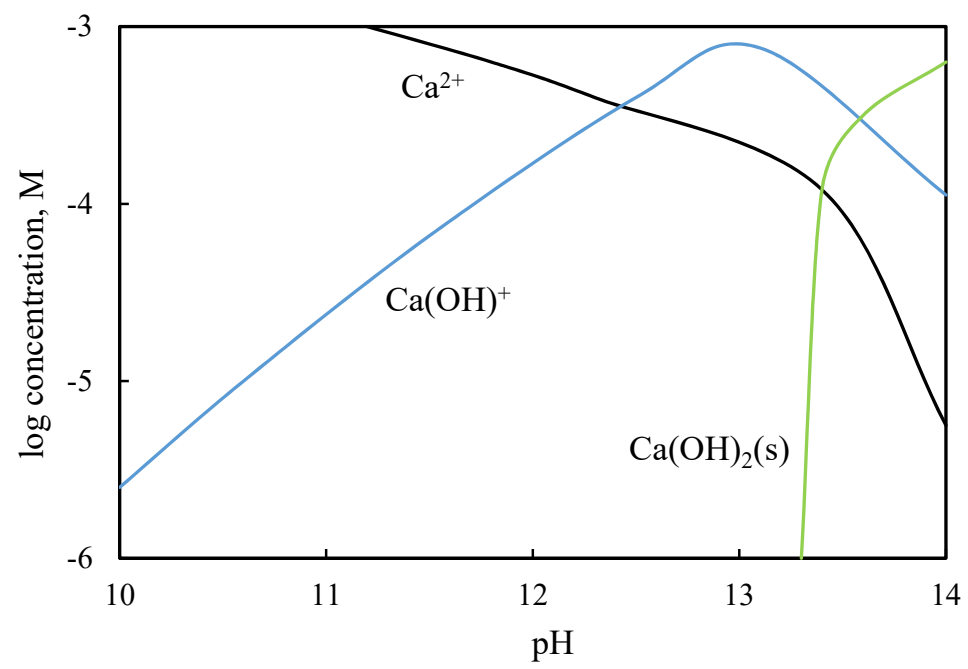

Figure 2. Species distribution diagrams of $\mathrm{Ca}^{2+}$ as a function of $\mathrm{pH}$ (total concentration $=1 \times 10^{-3} \mathrm{~mol} / \mathrm{L}$ ) (after [26]).

The adsorption of oleate ions on the activated quartz surface is considered chemisorption via forming covalent bonding. The adsorption can be described by the general electron donor/electron acceptor model (i.e., covalent bonding model); that is, the oxygen in the $\mathrm{COO}^{-}$functional group is the electron donor and the calcium is the electron acceptor [33,34]. Equations (1) and (2) show the reactions between the oleate ions and the $\mathrm{SiO}-\mathrm{Ca}(\mathrm{OH})$ on the quartz surface [26]:

$$
\begin{gathered}
\mathrm{SiO}-\mathrm{Ca}(\mathrm{OH})+\mathrm{RCOO}^{-} \rightarrow \mathrm{SiOCaOOCR}+\mathrm{OH}^{-} \\
2 \mathrm{SiO}-\mathrm{Ca}(\mathrm{OH})+(\mathrm{RCOO})_{2}^{2-} \rightarrow 2 \mathrm{SiOCaOOCR}+2 \mathrm{OH}^{-}
\end{gathered}
$$

The formation of SiOCaOOCR, a precipitate, is non-reversible. The presence of the hydrocarbon tail of the oleate molecule on the quartz surface renders the quartz surface hydrophobic.

A problem associated with using oleic acid in flotation is that these reagents exhibit low solubility and often require heating to enhance their activity, which significantly increases the process cost [35]. Changing oleic acid (or fatty acids) to its soap by the addition of caustic soda has been commonly used to increase collector solubility and efficiency. Some attempts have been made to modify fatty acids by changing their molecular structures for increased solubility and activity. Fuerstenau and Jia [36] showed that the addition of a second polar group to the fatty acid molecule could not only increase the solubility owing to the formation of hydrogen bonds between the polar group and water molecules, but also enhance the collector adsorption on the mineral surfaces owing to the increase in electrostatic attraction. Ogata, et al. [37] found that the saturated fatty acids modified by introducing a chlorine atom to the $\alpha$-carbon position could improve their solubility. More recently, Zhu, et al. [38] introduced a bromine atom to the $\alpha$-carbon position of lauric acid to improve its solubility, and the results suggested that the newly synthesized collector exhibited good activity at a relatively low 
flotation temperature $\left(15^{\circ} \mathrm{C}\right)$. Similarly, Luo, et al. [39] synthesized a new collector by introducing a bromine atom to the $\alpha$-carbon position of decanoic acid, and they found that the collector also exhibited good selectivity at $16{ }^{\circ} \mathrm{C}$ with improved solubility. Although these newly modified anionic collectors have better solubility and selectivity (even at low flotation temperatures), none of them have been applied in the iron ore flotation practice, probably because of the high synthesis cost.

The effect of ions in process water on reverse anionic flotation has also attracted attention. The presence of excessive polyvalent cations could be detrimental for reverse anionic flotation [40,41]. For example, the concentration of $\mathrm{Ca}^{2+}$, mainly sourced from lime addition, can be accumulated to an excessive level in the process water. $\mathrm{Ca}^{2+}$ also may get adsorbed on the ultrafine particles of hematite, rendering its surface positively charged to accommodate the adsorption of fatty acids, thus resulting in the loss of iron along with the ultrafine quartz. A large amount of cations will precipitate with $\mathrm{OH}^{-}$, which in turn hinders the flotation process. Only a couple of studies placed an emphasis on the role of anions in plant water. It was found that an anion in water has a greater depression than a cation at the same charge in the flotation of hematite, and an increase in the valence of anion leads to a drop in the adsorption of oleate on hematite $[42,43]$.

\subsection{Cationic Collectors}

Amines are widely used as collectors in the reverse cationic flotation of iron ores. Because a cationic collector carries a positively charged headgroup in water, the adsorption of the collector on a mineral surface is governed by the magnitude and sign of the surface charge of the mineral, which can be measured by a zeta potential meter or zeta probe [44,45].

The zeta potential of quartz in aqueous solution is $\mathrm{pH}$-dependent. Quartz hydrolyses in aqueous solution to form hydroxyl at the surface [30]. The surface hydroxylation achieves a maximum at the isoelectric point (IEP) [46], a pH value at which the net charge at the surface is zero. Below the IEP of quartz, the surface hydroxyl protonates and the quartz surface becomes positively charged, whereas above the IEP, the hydroxylated quartz deprotonates and becomes negatively charged. As shown in Figure 3, the IEP of quartz in an aqueous solution is about 2. The reverse cationic flotation of iron ores is normally performed at weak alkaline $\mathrm{pHs}$, where the surface of quartz is negatively charged. Note that hematite surface can also be hydrolyzed in aqueous solution $[47,48]$. Figure 3 shows that the IEP of hematite is between 6 and 7 , indicating that the hematite surface is also negatively charged at normal pHs of the flotation operations (e.g., 8-10.5), but to a lesser extent than the quartz surface. The cationic collector molecules would preferentially adsorb onto quartz instead of on hematite, especially when a depressant for hematite is used.

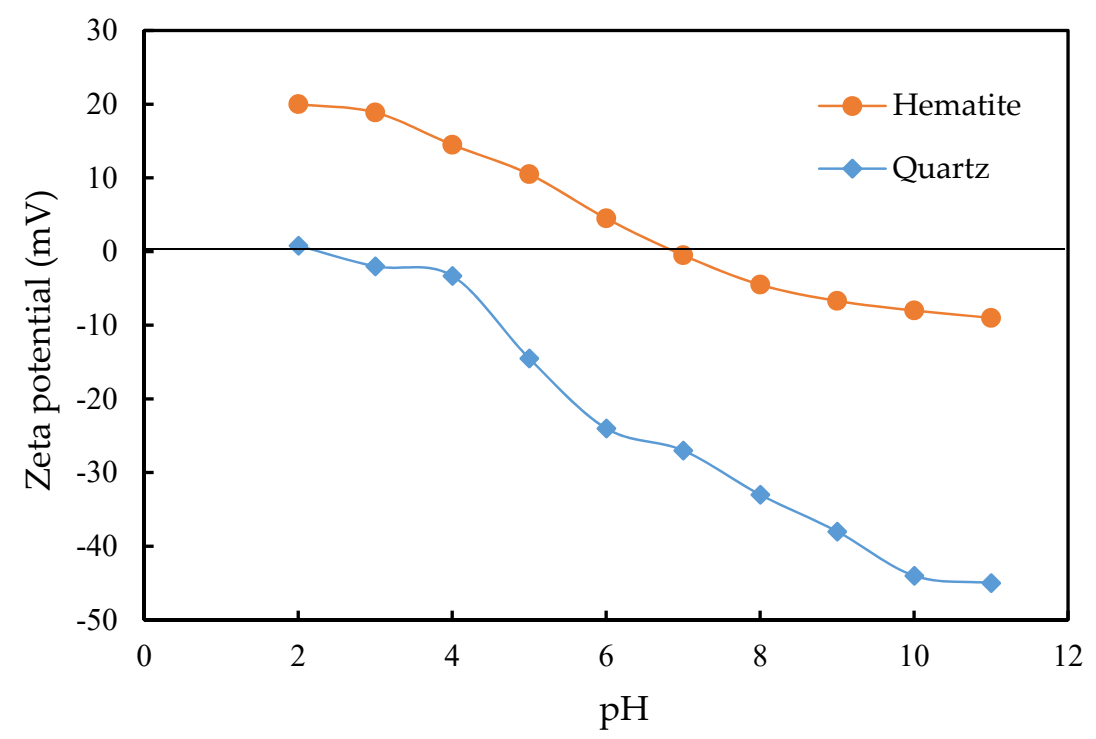

Figure 3. Zeta potential of quartz and hematite as a function of $\mathrm{pH}$ (after [49]). 
A cationic collector often forms different species in aqueous solutions, and which species dominate is dependent on $\mathrm{pH}$. For example, dodecylamine (DDA), the most commonly used collector in the early development stage of reverse cationic flotation of iron ores, may be present in various forms such as $\mathrm{RNH}_{3}{ }^{+},\left(\mathrm{RNH}_{3}\right)_{2}{ }^{2+}, \mathrm{RNH}_{2} \cdot \mathrm{RNH}_{3}{ }^{+}, \mathrm{RNH}_{2}$ (neutral molecule), and $\mathrm{RNH}_{2}$ precipitates in the solution phase, depending on $\mathrm{pH}$ and concentration [50]. Table 3 summarizes the equilibrium constants for dodecylamine aqueous species at total ionic concentration of $5 \times 10^{-2} \mathrm{~mol} / \mathrm{L}$. As depicted in Figure 4, the ionic forms $\mathrm{RNH}_{3}{ }^{+}$and $(\mathrm{RNH} 3)_{2}{ }^{2+}$ dominate at the $\mathrm{pH}$ range of 2 to 9 and the neutral molecule $\mathrm{RNH}_{2}$ precipitates at $\mathrm{pH}$ 10. The concentration of ion-molecular complex $\mathrm{RNH}_{2} \cdot \mathrm{RNH}_{3}{ }^{+}$ exhibits a maximum value at $\mathrm{pH}$ 10.5. At $\mathrm{pH}>10.5$, the primary species are $\mathrm{RNH}_{2}$ molecule and $\mathrm{RNH}_{2}$ precipitation. Filippov, et al. [1] noted that the most effective cationic collectors are hydrolyzed reagents that present both ionic and molecular species in the aqueous phase. Hence, the optimum $\mathrm{pH}$ for DDA as a collector should be 10.5, where the amount of ion-molecular complex $\mathrm{RNH}_{2} \cdot \mathrm{RNH}_{3}{ }^{+}$ reaches the maximum.

Table 3. Equilibrium constants for dodecylamine species in aqueous solution [40] (total ionic concentration $\left.=5 \times 10^{-2} \mathrm{~mol} / \mathrm{L}\right)$.

\begin{tabular}{cc}
\hline Equilibria & Constants \\
\hline $\mathrm{RNH}_{2} \rightleftharpoons \mathrm{RNH}_{2}(\mathrm{so})$ & $\mathrm{pK}_{s o}^{\prime}=4.69$ \\
$\mathrm{RNH}_{3}^{+} \rightleftharpoons \mathrm{RNH}_{2}+\mathrm{H}^{+}$ & $\mathrm{pK}_{a}^{\prime}=10.63$ \\
$2 \mathrm{RNH}_{3}^{+-} \rightleftharpoons\left(\mathrm{RNH}_{3}\right)_{2}^{2+}$ & $\mathrm{pK}_{a}^{\prime}=-2.08$ \\
$\mathrm{RNH}_{3}^{+}+\mathrm{RNH}_{2}{ }^{-} \rightleftharpoons\left(\mathrm{RNH}_{2} \cdot \mathrm{RNH}_{3}\right)^{+}$ & $\mathrm{pK}_{A B}^{\prime}=-3.12$ \\
\hline
\end{tabular}

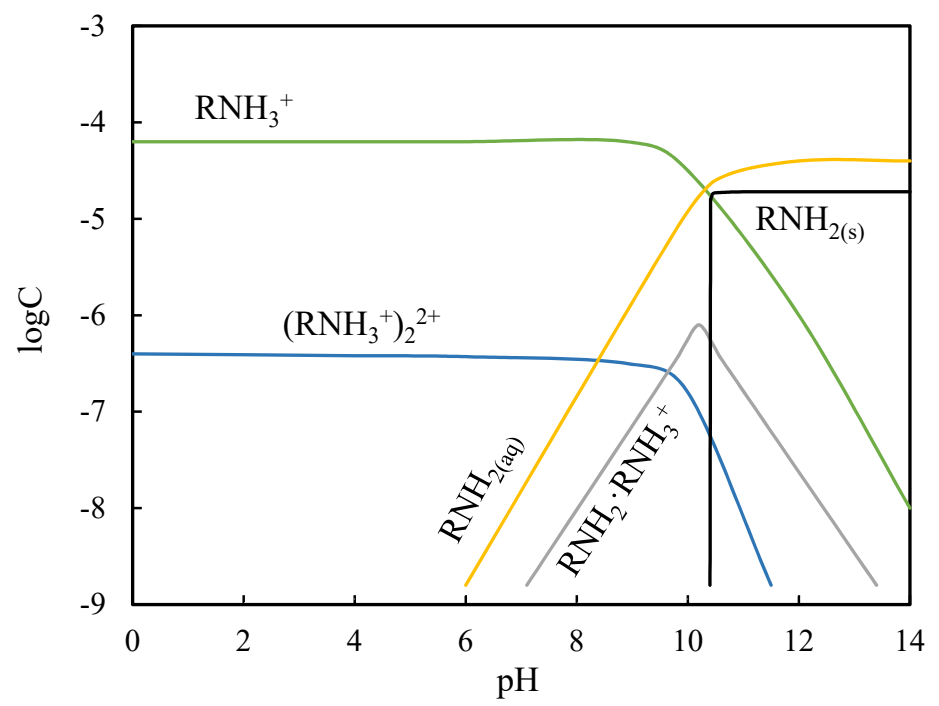

Figure 4. Species distribution diagram of dodecylamine as a function of $\mathrm{pH}$ (total concentration $=$ $\left.5 \times 10^{-5} \mathrm{~mol} / \mathrm{L}\right)($ after [40]).

The floatability of quartz also depends on the amount of amines adsorbed at the surface. At low concentrations (Figure 5A), the amine ions are adsorbed at the quartz surface, resulting primarily from electrostatic forces, and the hydrophobic amine tails increase the floatability of quartz [51,52]. When the amine concentration is increased, reaching the critical hemimicelle concentration (CHC), saturated monolayer hemimicelles are formed at the solid-liquid interface (see Figure 5B). At this concentration, the floatability of quartz reaches a maximum and the zeta potential is reversed from negative to positive, under which concentration the Stern layer acts against further adsorption [53]. Above the $\mathrm{CHC}$, the amine adsorption is driven by the association between hydrocarbon chains [54]. The polar head of the amine ions that associate with those already adsorbed on the surface might stay away from the surface owing to the repulsion between the ionic heads, and a bilayer is formed 
by tail-tail hydrophobic interaction (Figure 5C). This type of adsorption of the ions can lead to a hydrophilic quartz surface, thus decreasing quartz recovery in flotation [51,53,55]. A further increase in the concentration of the amine to its critical micelle concentration (CMC) will allow micelles to form in the bulk solution (see Figure 5D). Any further increase in the amine concentration will not affect the collector adsorption at the quartz surface. In short, the concentration of a cationic collector in flotation needs to be controlled at an appropriate concentration, and an overdose may be detrimental for quartz flotation. For dodecylamine hydrochloride (DAC), a typical cationic collector, the literature reports that its CMC varies between $1.25 \times 10^{-2} \mathrm{~mol} / \mathrm{L}$ and $1.38 \times 10^{-2} \mathrm{~mol} / \mathrm{L}[56,57]$.

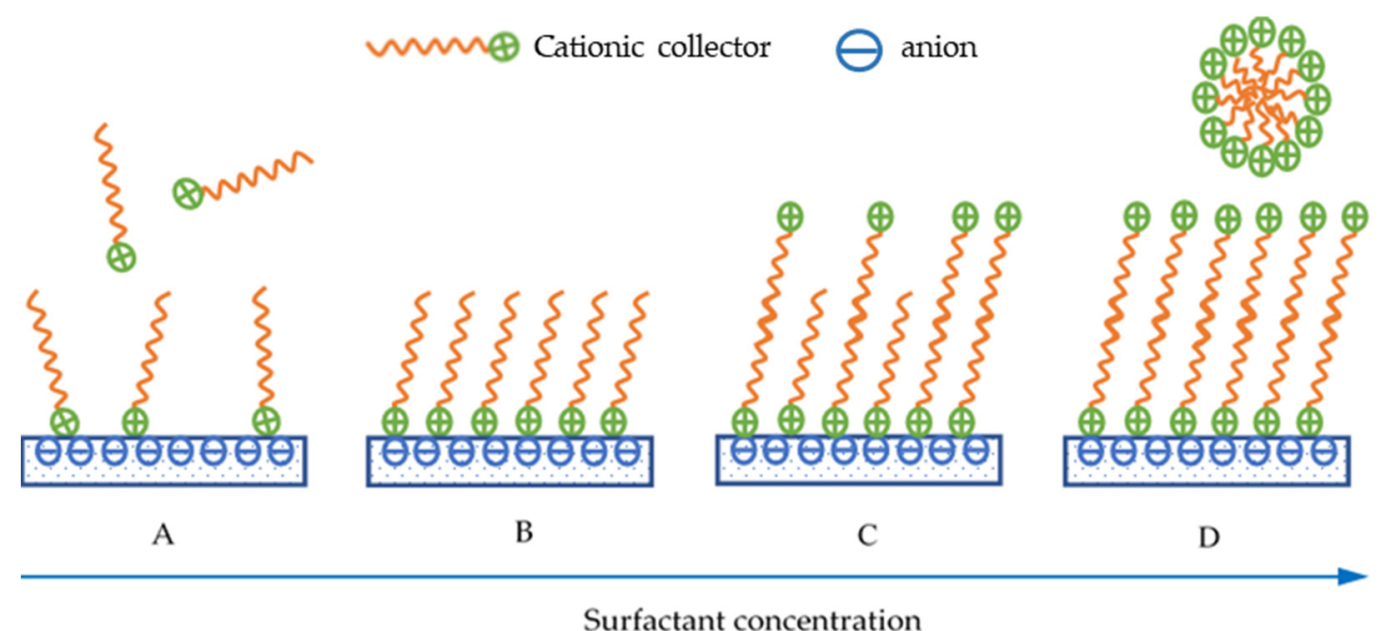

Figure 5. Speculated schematic model of a cationic collector/surfactant adsorption at the quartz/water interface over concentration. (A: concentration $<\mathrm{CHC}$; $\mathbf{B}$ : concentration $=\mathrm{CHC}$; : $\mathrm{CHC}<$ concentration $<\mathrm{CMC}$; D: concentration $=\mathrm{CMC})$

The molecular structure of a flotation collector is an important factor affecting its flotation performance. Primary alkylamine collectors used at the early stage of iron ore flotation technology development were abandoned in 1960s owing to their low solubility and activity [1]. The low solubility in water and low critical micelle concentration of alkylamines result in low adsorption density at the quartz surface. Quaternary ammonium salts exhibit higher solubility and better selectivity than alkylamine collectors [58]. Quaternary ammonium salts in water are in the form of ions at a wide range of $\mathrm{pH}$ and are, therefore, less sensitive to $\mathrm{pH}$ [59]. However, quaternary ammonium salts result in relatively low adsorption density at the quartz/water interface, primarily because of the strong electrostatic repulsions between the collector ions at the quartz/water interface [60]. Fuerstenau and Modi [61] showed that effective flotation of corundum would require a concentration of the trimethyldodecylammonium salt (a quaternary ammonium salt) 10 times higher than that of dodecylamine. Currently, ether amines and their salts have been widely used as collector in the reverse cationic flotation practice for upgrading iron ores. According to Araujo, et al. [9] and Fuerstenau and Jia [36], the addition of a second polar group to the molecule of the primary aliphatic amines increases the collector adsorption density at the mineral surfaces. The ether amines with the presence of one $-\mathrm{NH}_{2}$ functional group are named ether monoamines. In addition, a second $-\mathrm{NH}_{2}$ functional group could be inserted into the molecular structure, forming ether diamines. It is expected that ether diamines have higher solubility and selectivity compared with ether monoamines because the former has two hydrophilic moieties in one molecule [62]. Araujo, et al. [9] reported that ether diamines would exhibit superior selectivity in coarse silicate particle flotation. Some studies suggested that a mixture of monoamines and diamines may be more efficient for the flotation of iron ores with a wider particle size distribution $[1,63,64]$.

Some progress for developing new types of cationic collectors was made in the past several years. Huang, et al. [53] synthesized a cationic gemini collector dimethyl-dodecyl-ammonium bromide (EBAB). 
Gemini collectors contain two hydrophilic head groups (functional groups) and two hydrophobic tails covalently linked through a spacer [65]. Figure 6 shows a schematic model of a cationic gemini collector adsorption at the quartz surface. The EBAB exhibited higher solubility and selectivity than dodecylamine hydrochloride. Similarly, Weng, et al. [66] developed an ester-containing quaternary ammonium collector M-302. They reported that M-302 showed better collecting power and higher solubility compared with dodecylamine hydrochloride. Note that EBAB and M-302 could be used at neutral $\mathrm{pH}$, which is another advantage over the other collectors normally used. However, no industrial applications of the two collectors have been reported yet. Recently, ionic liquids (ILs) as collector in the reverse iron ore flotation have also been tested. ILs are a group of salts having poorly coordinated ions, and are in liquid state at a temperature below $100{ }^{\circ} \mathrm{C}$ or even at ambient temperature. Sahoo and his co-authors have tested quaternary ammonium-based ionic liquids (Aliquat-336 and Tricaprylmethyl ammonium salicylate) as flotation collector of quartz [67-69]. They found that the ionic liquids exhibited stronger adsorption at the quartz surface via electrostatic adsorption compared with DDA or cetyltrimethylammonium bromide (CTAB). Those ionic liquids can be used at a wide range of $\mathrm{pH}$ and can even exhibit great selectivity at a neutral $\mathrm{pH}$. Currently, the study of using ionic liquids as collector for iron ores is still at the early stage and no ILs are being used in the industrial iron ore flotation operations.

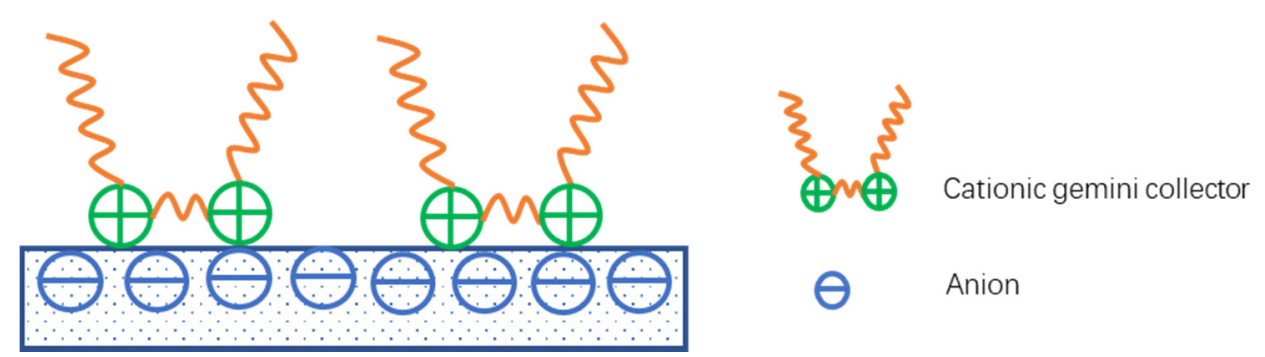

Figure 6. Schematic model of a cationic gemini collector adsorption at the quartz surface.

It is noteworthy that the presence of cations has a detrimental impact on quartz flotation with cationic collectors. The commonly present metal cations in iron ore flotation such as $\mathrm{Ca}^{2+}$ and $\mathrm{Mg}^{2+}$ are either sourced from hard water used at the processing plants or released from gangue minerals (e.g., calcite and Mg-bearing siderite) [70]. The concentration of cations can be very high after accumulation in the process water and significantly depress the flotation of quartz when cationic collectors are used. As shown in Figure 7, the adsorption of metal cations on quartz surface can reverse the surface charge from negative to positive, which prevents the adsorption of cationic amine on the quartz surface owing to electrostatic repulsion [43,71]. Hence, the concentration of metal cations in process water should be closely monitored. The concentration of cations can be reduced by increasing $\mathrm{pH}$ to hydroxylate the cations and form precipitates [72]. Different from cations, anions exhibit a promotive effect on the reverse flotation of iron oxides, in improving the recovery of $\mathrm{Fe}$ and lowering the $\mathrm{SiO}_{2}$ content in the concentrate. This is probably owing to the formation of the inner and outer sphere binuclear or polynuclear surface complexes on mineral surfaces at near-neutral $\mathrm{pH}$ values, providing less suitable leaving groups for detachment into the water, thus successfully inhibiting the dissolution of metal ions with a higher valence [43]. In addition, anions at a higher valence (e.g., $\mathrm{SO}_{4}{ }^{2-}$ ) tend to have a more significant effect than anions with a lower valence (e.g., $\mathrm{Cl}^{-}$) [73].

In summarizing the above two sections, one can see that cationic collectors adsorb on the mineral surface via physisorption (electrostatic interaction), while anionic collectors adsorb on the mineral surface mainly by chemisorption. The electrostatic interaction occurs by means of the positively charged cationic collector adsorbing on the negatively charged mineral surface. The chemisorption of anionic collectors on mineral surfaces is governed by forming covalent bonding between the anionic collectors and the multivalent ions adsorbed on the mineral surface. The adsorption of these two types of collectors at the mineral surface is $\mathrm{pH}$-dependent. The collectors for reverse iron ore flotation 
were advanced via modifying the collector structure, with the aim of improving their solubility and selectivity.

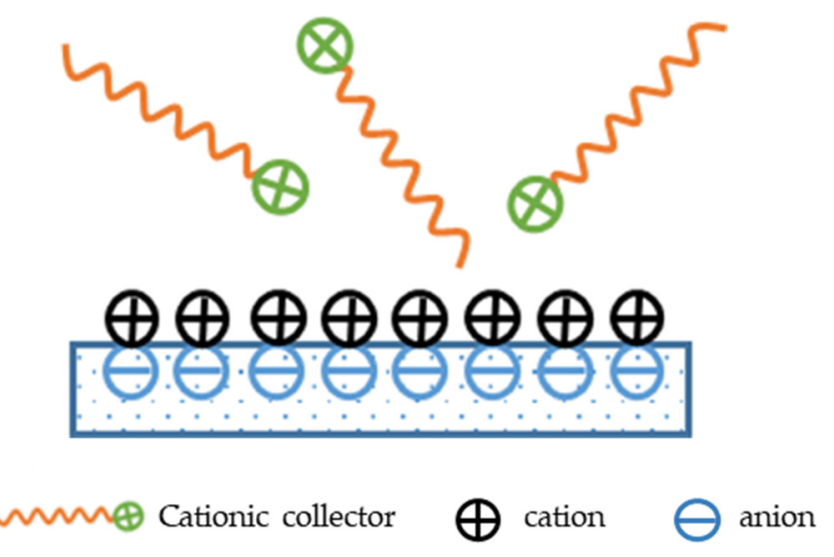

Figure 7. Effect of cations on the adsorption of amines on the quartz surface.

\subsection{Collector Mixtures}

The use of collector mixtures has become common in flotation practice. Different mixtures of collectors were tested to remove quartz from other minerals. These mixtures mainly include anionic/anionic collectors, anionic/cationic collectors, and ionic/non-ionic combinations [10].

The application of mixed anionic collectors in reverse iron ore flotation has been long investigated [74-76]. The use of mixture of anionic collectors aims to increase the collector solubility in order to reduce the collector consumption. As mentioned in Section 2.1, oleic acid and its soaps have low solubility, posing a limitation on their use in iron ore flotation practice. The solubility of oleic acid and its soaps could be improved by adding some hydrophilic functional groups to their molecular structures. Another approach to improving their solubility is simply adding some anionic collectors that have better solubility in water. In general, for the fatty acids with the same carbon atom number, the solubility increases with the increasing number of double bonds in their molecules (i.e., degree of unsaturation) [76]. Rama Murthy and Mallikajunan [74] used soaps made from Bombax malabarica oil and shark liver oil to float barium-activated quartz. Bombax malabarica oil contains $43 \%$ oleic acid and $31.3 \%$ linoleic acid. The shark liver oil contains $24.9 \%$ palmitic acid, $11.2 \%$ palmitoleic acid, $11.1 \%$ stearic acid, $19.6 \%$ oleic acid, and $22.3 \%$ gadoleic acid. The degree of unsaturation of Bombax malabarica oil is higher than that of the shark liver oil. These researchers found that the soap from Bombax malabarica oil was superior to the soap from the shark liver oil in quartz flotation. Lin, et al. [75] developed an anionic collector RA-315, with the main components being fatty acids and abietic acids. The abietic acids have a much higher degree of unsaturation than fatty acids. This collector exhibits good solubility and selectivity and has been widely used in the reverse flotation of iron ore in China. Wei, et al. [76] used a purified cotton seed fatty acid as collector in the reverse flotation of an iron ore. The purified cotton seed fatty acid contains oleic acid and linoleic acid. The purification process aimed to increase the content of linoleic acid in the collector blend as the degree of unsaturation of linoleic acid is higher than that of oleic acid. Wei, et al. [76] reported that this collector exhibited good selectivity at ambient temperature.

The effectiveness of using anionic-cationic mixtures in flotation has also been recognized. Vidyadhar and Hanumantha Rao [11] found that using the mixture of a cationic collector (tallow-1,3-diaminopropane) and an anionic collector (sodium dodecyl sulfonate) could achieve a superb separation of feldspar from quartz at pH 2. Wang, et al. [12] observed that the mixture of sodium oleate and dodecylamine acetate could enhance the separation of muscovite from quartz at $\mathrm{pH}$ 10. Huang, et al. [77] investigated the adsorption of dodecyltrimethylammonium bromide (DTAB), dodecylpyridinium bromide (DPB), sodium dodecylbenzenesulfonate (SDBS), and sodium dodecyl sulfate (SDS) on silica gel at pH 5.6 in individual aqueous solutions, and DTAB-SDBS and DPS-SDS 
binary mixed solutions. It is expected that the cationic collectors should be strongly adsorbed on negatively charged silica gel, but no significant adsorption of anionic collectors should occur owing to electrostatic repulsion. However, in mixed collector systems, the adsorption of cationic and anionic collector ions would increase simultaneously, and the surface excess of cations could match that of anionic ions. Figure 8 illustrated a possible reason that the anionic collector ions are co-adsorbed specifically with cations as ion pairs at the non-charged sites of quartz through the van der Waals interaction [10]. An increased adsorption density of collectors on the quartz surface would result in enhanced hydrophobicity of the quartz surface.

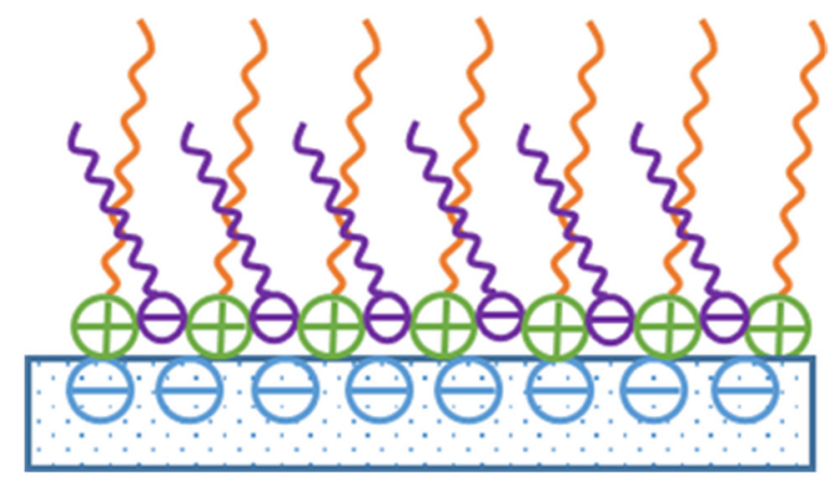

\section{Antionic collector me Anionic collector $\ominus$ Anion}

Figure 8. Co-adsorption of cationic and anionic collectors at the quartz surface.

The metallurgical results for the reverse flotation of iron ores can also be improved using a combination of ionic collectors (anionic or cationic collectors) and non-ionic surfactants, such as fatty alcohols [13,78,79]. Non-ionic alcohols cannot adsorb on the quartz surface, while their presence could enhance the adsorption of ionic collector. Vidyadhar, et al. [79] observed that the presence of 1-dodecanol enhanced the adsorption of the dodecylamine ions at the quartz surface at pH 6-7 and resulted in a higher quartz recovery. Filippov et al. [13] found that the addition of a C13-rich iso-alcohol to ether diamine increased the quartz flotation recovery from 52 to $84 \%$ at $\mathrm{pH} 10$. In addition, Filippov, et al. [78] observed that adding iso-alcohols to ether diamine could also improve the floatability of Fe-bearing mica silicates at $\mathrm{pH} 8$, while use of the amine alone exhibited little selectivity on the silicates. It is likely that the adsorption of ionic collector is enhanced by the presence of nonionic surfactant owing to both the hydrophobic chain-chain interaction and the reduction of electrostatic repulsion between ionic head groups that are shielded from each other by the nonionic surfactant molecule [10,80]. Figure 9 shows a schematic of coadsorption of cationic collector and alcohol on the surface of quartz. The phenomenon may also be explained by Leja-Schulman's penetration theory [81]; that is, a diffused monolayer of collector molecules is formed at the quartz surface, and in the meantime, the insoluble non-ionic surfactant (e.g., fatty alcohols) forms the diffused molecular monolayers at the air/water interface. As soon as the air bubble contacts the quartz surface, the surfactant molecules at the air/water interface can penetrate the diffused collector monolayer at the quartz surface and adsorb strongly onto the quartz surface, greatly increasing quartz recovery by increasing the local surfactant concentration and local hydrophobic character of the quartz surface. It is, therefore, expected that adding alcoholic frothers may enhance the flotation performance, although these frothers are normally not needed in iron ore flotation. 


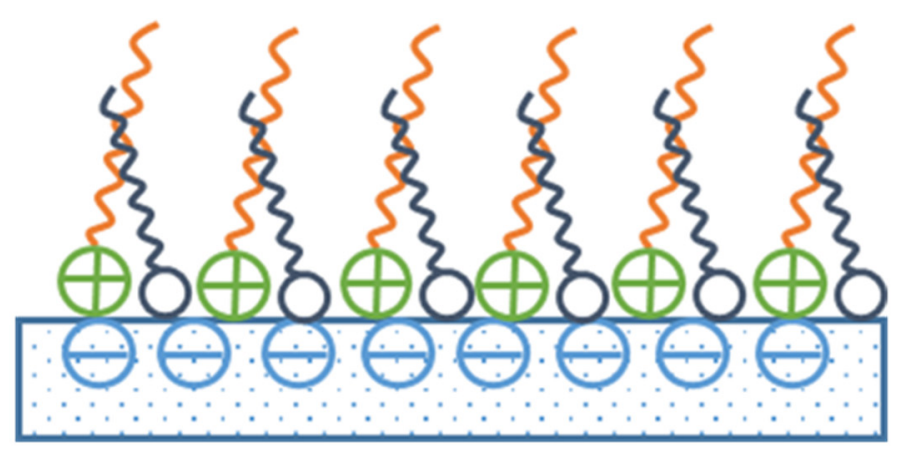

Anion

Figure 9. Coadsorption of cationic and nonionic surfactant at the quartz surface.

\section{Collectors for Non-Quartz Gangue Minerals}

\subsection{Alumina-Bearing Minerals}

The alumina-bearing minerals present in the iron ore include gibbsite, kaolinite, montmorillonite, illite, diaspora, and corundum. Gibbsite $\left(\mathrm{Al}(\mathrm{OH})_{3}\right)$ and kaolinite $\left(\mathrm{Al}_{2} \mathrm{Si}_{2} \mathrm{O}_{5}(\mathrm{OH})_{4}\right)$ are the two main alumina-bearing minerals present in iron ores [82]. Removal of kaolinite and gibbsite from iron ores is aimed at reducing the content of $\mathrm{Si}$ and $\mathrm{Al}$ in the flotation concentrate.

Separation of gibbsite from iron oxides such as hematite by means of flotation is difficult owing to little difference in surface characteristics between gibbsite and hematite. Generally, hematite and gibbsite have a similar crystal structure. The cations are trivalent and have common chelation characteristics. In addition, the bond distances of $\mathrm{Fe}-\mathrm{Fe}$ and $\mathrm{Al}-\mathrm{Al}$ are very similar (i.e., $2.850 \AA$ and $2.852 \AA$, respectively) [83]. Hence, gibbsite and hematite have a similar surface charge and almost identical complexation characteristics. It is, therefore, challenging to separate gibbsite from iron oxides via flotation. Thella, et al. [84] argued that the direct production of iron ore concentrate by flotation from iron ores containing high alumina (mainly gibbsite) was challenging, owing to complex mineralogy. Desliming was indispensable before flotation to remove ultrafine gangue particles and to increase iron grade. It was found that the combination of classification and reverse cationic flotation using monamine as collector could achieve a high grade iron concentrate having $64.5 \% \mathrm{Fe}, 2.2 \% \mathrm{Al}_{2} \mathrm{O}_{3}$, while the $\mathrm{Fe}$ recovery was only $28.7 \%$ [84]. Kumar, et al. [85] reported that selective flocculation for alumina-rich iron ore slimes using carboxymethyl cellulose as flocculant could facilitate the separation of gibbsite from hematite. The experimental results show that a final concentrate of $64.4 \% \mathrm{Fe}, 4.2 \% \mathrm{Al}_{2} \mathrm{O}_{3}$, and $1.9 \%$ silica with a yield of $56 \%$ could be obtained from a feed containing $56.5 \% \mathrm{Fe}, 7.0 \%$ alumina, and $4.9 \%$ silica [85].

Removal of kaolinite in iron ore flotation is possible, but not straightforward. There are multiple interactions between kaolinite and depressant and/or collector [2]. It was found that selective depressing of hematite against kaolinite using starch is feasible, subject to strict $\mathrm{pH}$ control. Ma and Bruckard [86] observed that starch adsorption on kaolinite would significantly decrease with the increasing $\mathrm{pH}$ from 7 to 10.5. Starch showed an extremely low affinity towards kaolinite at $\mathrm{pH} 10.5$, where iron oxides can be well depressed by starch. As reverse cationic flotation of iron ores is normally performed at alkaline $\mathrm{pH}$ around 9-10.5, where iron ores can be well depressed while kaolinite is not, it is possible to separate kaolinite from iron ores if kaolinite could be rendered hydrophobic using a suitable collector.

It was, however, found that the amine collectors normally used in reverse iron ore flotation would interact with kaolinite in a way different from that with quartz. Amine collectors lead to effective kaolinite flotation in acidic solutions, while little adsorption of collectors occurs at alkaline $\mathrm{pH}[19,21]$. Figure 10 shows the zeta potential of kaolinite as a function of $\mathrm{pH}$. The IEP of kaolinite is at $\mathrm{pH}$ $4.2[19,87]$. Above its IEP, the negative zeta potential of kaolinite increases with the increasing $\mathrm{pH}$, hence the adsorption of collector on kaolinite increases. However, the flotation of kaolinite decreases 
with an increase in collector adsorption. $\mathrm{Hu}$, et al. [19] investigated the anomalous flotation behavior in kaolinite solution using dodecyl amine (DDA) as collector based on crystal structure considerations and particle aggregation phenomena. Although the silica (001) and alumina (001) basal planes of kaolinite are negatively charged, DDA has a stronger interaction with the (001) plane than with the $(00 \overline{1})$ alumina plane, which can be attributed to the difference in the structure at the (001) and $(00 \overline{1})$ planes. The self-aggregation between $(00 \overline{1})$ faces and the edge planes and the adsorption of DDA at the silica (001) plane cause the kaolinite to aggregate hydrophobic, and good floatability is achievable in acidic solution. In alkaline solution, the kaolinite particles are dispersed. With the presence of DDA, hydrophobic aggregation appears to occur in alkaline solution between the (001) planes owing to the adsorbed DDA, and thus the hydrophilic $(00 \overline{1})$ faces are exposed and flotation is not achievable [19]. As silica needs to be removed in an alkaline solution when an amine is used as collector, it is difficult to remove kaolinite and silica together in iron ore flotation using amine collectors. It may be possible, however, to sequentially remove kaolinite and silica from iron oxides, namely removing kaolinite at acidic $\mathrm{pHs}$ and removing silica at alkaline $\mathrm{pHs}$.

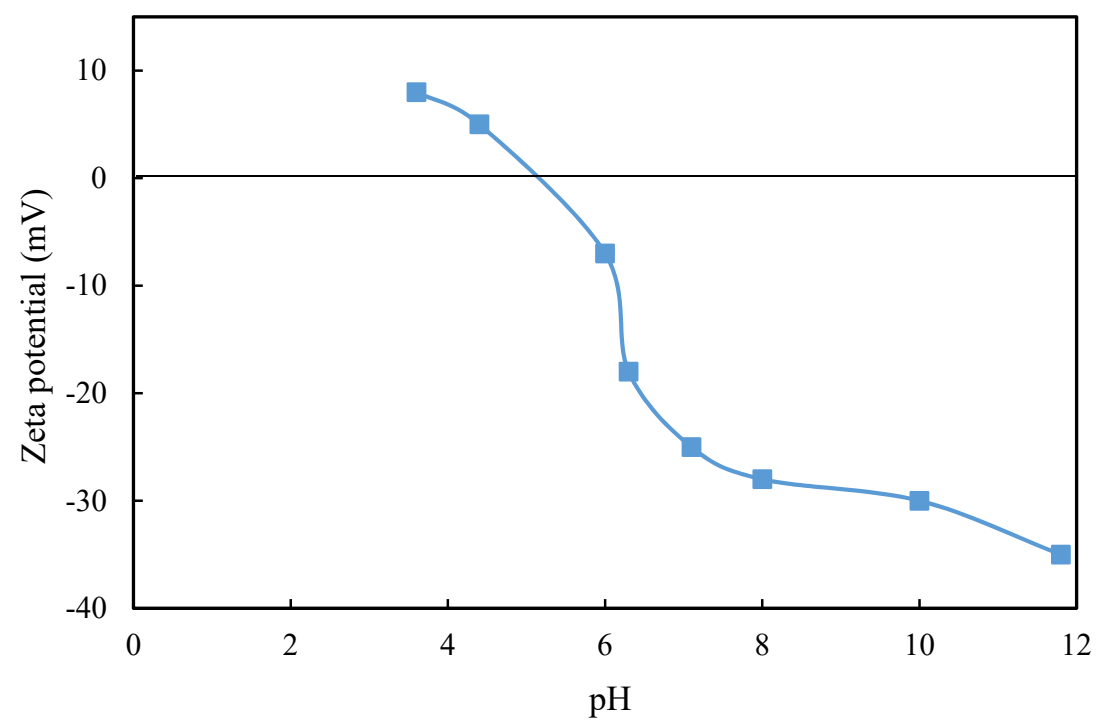

Figure 10. Zeta potential of kaolinite as a function of $\mathrm{pH}$ (after [13]).

Ammonium quaternary salts can be used as collector for kaolinite in reverse iron ore flotation. As mentioned before, quaternary ammonium salt collectors are less influenced by $\mathrm{pH}$ [59]. Rodrigues, et al. [88] showed that effective separation between kaolinite and hematite was achieved using DTAB at the $\mathrm{pH}$ range of 4 to 10 . Note that, at this $\mathrm{pH}$ range, the quaternary ammonium salt can also be used as collector for quartz removal, so it is possible to simultaneously remove kaolinite and quartz.

The current understanding of the interaction between anionic collector and kaolinite is limited. According to the work of $\mathrm{Xu}$ et al. [89], sodium oleate, the prevailing anionic collector used in reverse anionic flotation, has strong affinity with $\mathrm{Al}$ sites at kaolinite surface at $\mathrm{pH}$ 8-9. At this $\mathrm{pH}$ range, however, the amount of sodium oleate adsorbed on the quartz surface is low. It might be possible to remove kaolinite and quartz separately at different $\mathrm{pHs}$. More studies are needed to explore the possibility of using anionic collector to remove kaolinite from iron ores.

The effectiveness of using a temperature-sensitive polymer, poly ( $\mathrm{N}$-isopropyl acrylamide) (PNIPAM), as a process aid in the flotation of kaolinite was demonstrated by Li and Franks [90]. The polymer acts as dual-function flocculant and collector. The polymer preferentially adsorbs on kaolinite via hydrogen bonding to cause flocculation of kaolinite particles and to render the particle surface hydrophilic at room temperature, whereas at a temperature higher than the polymer's critical solution temperature (approximately $32{ }^{\circ} \mathrm{C}$ ), adsorption of the polymer molecules induces 
a hydrophilic/hydrophobic transition. A high flotation recovery of kaolinite particles was achieved at $50{ }^{\circ} \mathrm{C}$, which was attributed to flocculation and increased surface hydrophobicity, thus obviating the need for the addition of a conventional flotation collector. Given the function of flocculating the fines, this polymer should exhibit good performance for the ores carrying a significant amount of fine particles. However, this polymer requires heating during flotation, which will increase the operating cost.

\subsection{Phosphorus-Bearing Minerals}

Phosphorus is a harmful element in steel-making, causing product defects such as increased hardness and brittleness and decreased ductility [6]. The phosphorus in iron ore deposits occurs primarily as apatite (general molecular format $\mathrm{Ca}_{5}\left(\mathrm{PO}_{4}\right)_{3}(\mathrm{~F}, \mathrm{Cl}, \mathrm{OH})$ ). In what follows, the interactions between collectors and apatite in the separation of apatite from iron ores via flotation are discussed.

In anionic flotation of apatite, fatty acids (e.g., oleic acids) and their soaps are primarily used as collector [91-93], often in conjunction with hydrocarbon supplements (e.g., kerosene and fuel oil), to reduce the collector consumption [94]. Su, et al. [95] separated apatite from magnetite with a modified fatty acid collector (Atrac-1562) at pH 8.5-9.0 and at a pulp temperature of approximately $20{ }^{\circ} \mathrm{C}$. Kou, et al. [96] carried out phosphate flotation using a refined tall oil fatty acid at a dosage of $0.45 \mathrm{~kg} / \mathrm{t}$ at $\mathrm{pH} 10$ with a 9:8 (by mass) concentration ratio of fatty acid to diesel. Cao, et al. [97] employed a mixed collector (i.e., $54 \mathrm{wt}$ \% oleic acid, $36 \mathrm{wt}$ \% linoleic acid, and $10 \mathrm{wt}$ \% linolenic acid) for apatite flotation at $\mathrm{pH} 9.5$ and at a pulp temperature of approximately $23{ }^{\circ} \mathrm{C}$. The interaction between the carboxyl group of the fatty acids and $\mathrm{Ca}(\mathrm{OH})^{+}$ions exposed at the mineral surface was considered the mechanism of attaining the flotation of the apatite [98], which is the same as the adsorption mechanism of oleic acid with activated quartz (see Section 2.1). Furthermore, given that apatite is a sparingly soluble mineral, it has been reported that its dissolution accounts for the floatability of apatite. Finkelstein [99] argued that, immediately after leaving the mineral lattice, $\mathrm{Ca}^{2+}$ ions interact with the oleate molecules. The formed calcium oleate then precipitates and renders the mineral surface hydrophobic. Horta, et al. [98] found that the apatite more dissolvable in water could provide more $\mathrm{Ca}^{2+}$ ions and exhibit better floatability. It was concluded that, in general, igneous apatite (e.g., fluorapatite, $\left.\mathrm{Ca}_{10}\left(\mathrm{PO}_{4}\right)_{6} \mathrm{~F}_{2}\right)$ bears better solubility than sedimentary apatite (e.g., carbonate-fluorapatite, $\left.(\mathrm{Ca}, \mathrm{Na}, \mathrm{Mg})_{10}\left(\mathrm{PO}_{4}, \mathrm{CO}_{3}\right)_{6}(\mathrm{~F}, \mathrm{OH})_{2}\right)$ [98].

The use of oleic acid in flotation requires relatively high temperatures, thus the added operating cost associated with using oleic acid is a concern [100]. At ambient temperature, alkyl hydroxamic acid mixed with alcohol is an effective collector for phosphate flotation (Miller et al. [94]). The flotation response demonstrated a very weak $\mathrm{pH}$ dependence for the hydroxamic acid collector, and the natural $\mathrm{pH}$ was found to be satisfactory for apatite flotation in most cases. Although the newly developed collector showed improved performance for phosphate flotation, it has found limited use in industry owing to its high cost [97].

Flotation of apatite using cationic collectors was also studied. Figure 11 shows the zeta potential of apatite as a function of pH. The IEP of apatite is 5.4 [22]. Soto and Iwasaki [101] investigated the effect of $\mathrm{pH}$ on apatite flotation using octadecylamine and found that apatite flotation was insensitive to the pulp $\mathrm{pH}$. They noted that the electrostatic adsorption may not fully account for the flotation phenomena; flotation of apatite below its IEP with octadecylamine was attributed to the chemical interaction between the collector and the mineral surface and, above its IEP, the collector would be adsorbed on the negatively charged apatite surface through electrostatic attraction. A similar observation was made by Moudgil and Ince [22] when separating apatite from dolomite using dodecylamine as collector. More recently, Nunes, et al. [6] reported that wavellite $\left[\mathrm{Al}_{3}\left(\mathrm{PO}_{4}\right)_{2}\left(\mathrm{OH}_{\text {, }}\right.\right.$ F) $)_{3} \cdot 5 \mathrm{H}_{2} \mathrm{O}$ ], a secondary phosphate mineral, exhibited around $100 \%$ floatability at pH 8.2 with Flotigam EDA (an industrial amine collector) and at pH 9.8 with octylamine. They attributed the adsorption of amines on wavellite to both chemical and electrostatic interactions. 


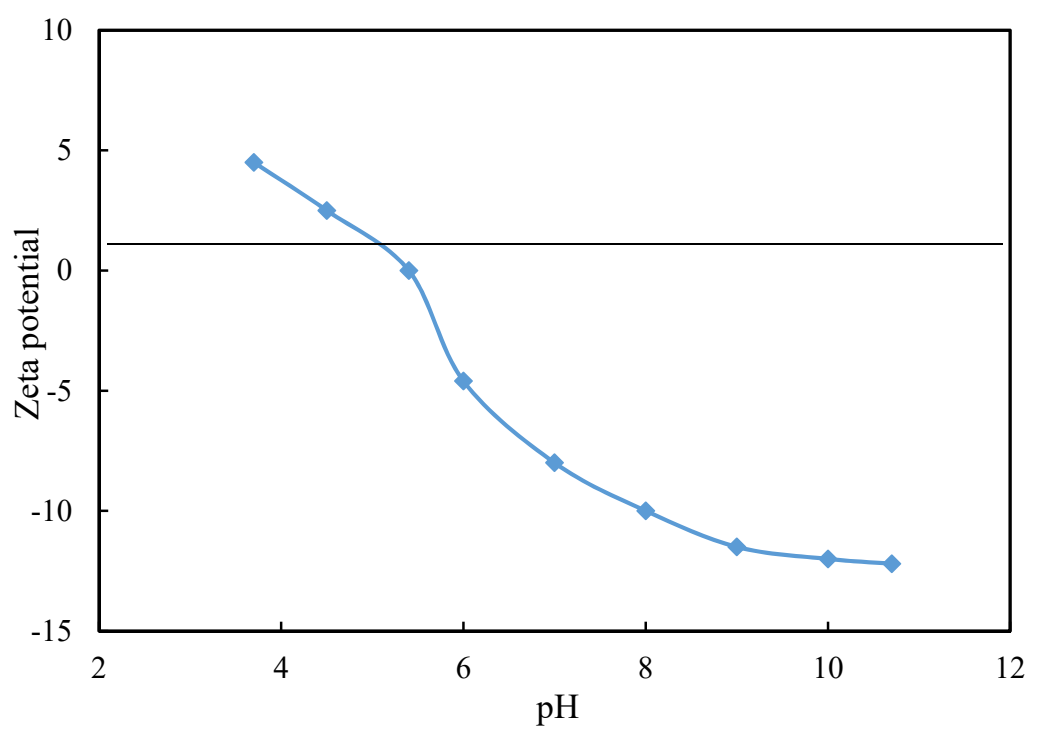

Figure 11. Zeta potential of apatite as a function of $\mathrm{pH}$ (after [16]).

\subsection{Iron-Bearing Carbonates}

Siderite $\left(\mathrm{FeCO}_{3}\right)$ is the most abundant non-oxide iron-bearing carbonate in iron ores [1]. As its theoretical grade is only $47.46 \%$, siderite is generally treated as gangue mineral and needs to be removed from the concentrate. Note that iron ores associated with siderite or other carbonate minerals are referred to as refractory ores [102-104]. The beneficiation of siderite via the combination of flash magnetizing roasting and flotation has been reported in China [105], but no industrial application is commissioned yet.

Siderite cannot be readily removed together with quartz in the reverse flotation of iron ores using anionic collectors such as fatty acid, despite that fatty acids have been widely used in the flotation of quartz (see Section 2.1) or many carbonates [106]. The presence of siderite can impose a detrimental effect on separating quartz from iron oxides when fatty acids are used as collector. As a salt-type mineral, siderite has a relatively high solubility. The dissolved mineral species can reach a high concentration. Figure 12 shows the species distribution diagram of siderite in aqueous solutions [16]. The dissolved mineral species can undergo several reactions such as hydrolysis, adsorption, and surface and bulk precipitations, which might inhibit selective interactions between the collector and other minerals [107-109]. Luo, et al. [16] used sodium oleate, calcium chloride, and starch as collector, activator, and depressant, respectively, in the flotation of a mixture of hematite, siderite, and quartz at $\mathrm{pH}$ 11.4. They found that siderite adversely affected the floatability of quartz, which was attributed to the adsorption of $\mathrm{CaCO}_{3}$ precipitations at the quartz surface. As shown in Figure 12, the concentration of $\mathrm{CO}_{3}{ }^{2-}$ increases significantly with the increasing $\mathrm{pH}$. The appearance of $\mathrm{CaCO}_{3}$ precipitations was caused by reaction of $\mathrm{Ca}^{2+}$ from the hydrolysis of $\mathrm{CaCl}_{2}$ and $\mathrm{CO}_{3}{ }^{2-}$ from dissolved species of carbonate minerals. Starch can adsorb on the $\mathrm{CaCO}_{3}$ precipitated at the quartz surface and then depress the quartz [110].

It is possible to separately remove siderite and quartz from iron oxides using anionic collectors. Sis and Chander [111] observed that, in anionic flotation, at acidic or neutral pH 5-7, siderite had good floatability, probably because siderite dissolves $\mathrm{Fe}^{2+}$ species below $\mathrm{pH} 7.6$ [46]. Anionic collector can interact with the dissolved $\mathrm{Fe}^{2+}$ species and precipitate at the siderite mineral surface. The anionic flotation of quartz is, however, operated at strongly alkaline $\mathrm{pH}[24,35,112]$. A two-step process can thus be used to remove these two impurities at different pHs. Zhang [113] demonstrated the two-step separation of siderite and quartz from hematite, in which siderite was floated under a neutral $\mathrm{pH}$ condition in the first step using sodium oleate as collector, and then the concentrate was refloated via reverse flotation with sodium oleate as collector under a strong alkaline condition to separate quartz from hematite. 


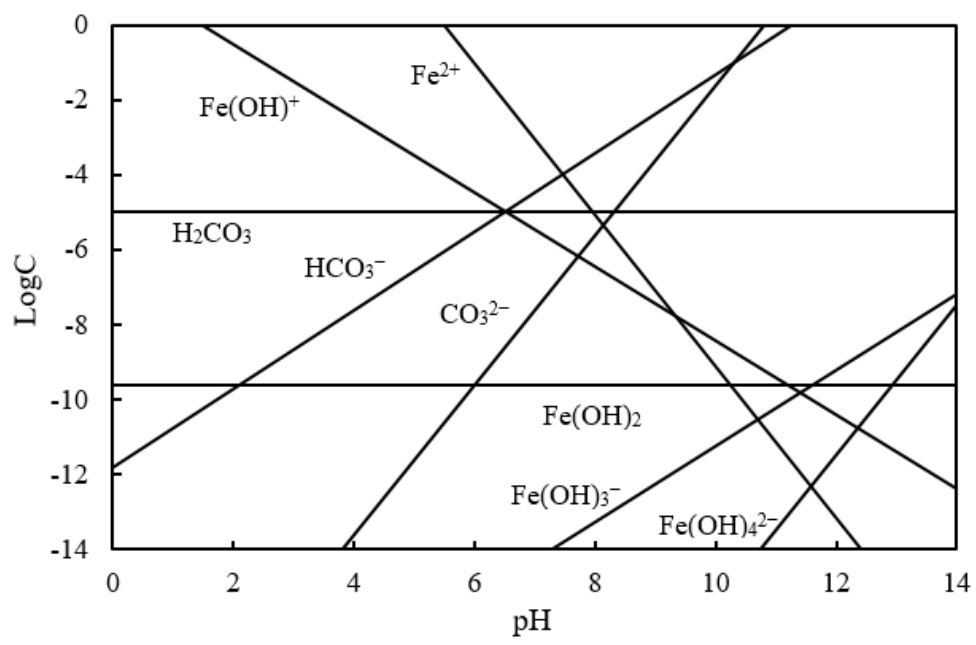

Figure 12. Species distribution diagram of siderite in aqueous solution at $25^{\circ} \mathrm{C}$ (after [5]).

Scarce information on flotation separation of siderite from iron oxides using cationic collector is available. Figure 13 shows the zeta potential of siderite as a function of $\mathrm{pH}$, from which one can see that the IEP of siderite is around 7. Ignatow [46] employed a cationic collector (i.e., dodecylpyridinium chloride, $\mathrm{DPCl}$ ) to float siderite at various $\mathrm{pHs}$ and achieved flotation recoveries of $60 \%$ at a $\mathrm{pH}$ above 12. At this $\mathrm{pH}$ range, $\mathrm{DPCl}$ would be adsorbed onto negatively charged siderite, matching the characteristics of electrostatic interaction. Ignatow [46] proposed an adsorption mechanism of DPCl with siderite; that is, the ions were adsorbed through an exchange reaction involving the $\mathrm{DP}^{+}$ion and $\mathrm{FeOH}$ species at the siderite surface. Abido [114] also observed that siderite had a strong interaction with dodecylamine at $\mathrm{pH} 10.5$.

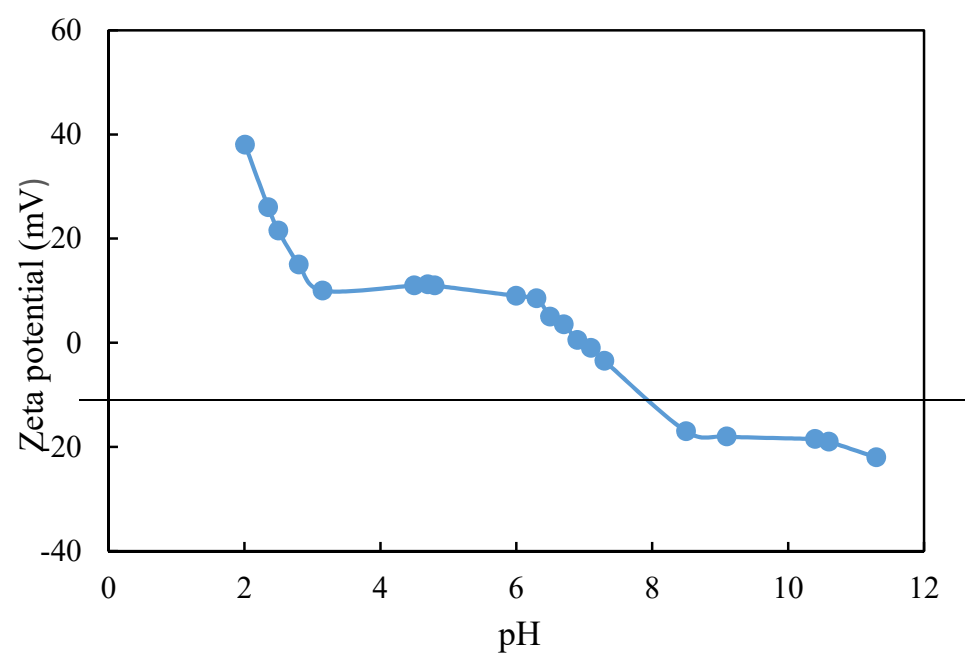

Figure 13. Zeta potential of siderite as a function of $\mathrm{pH}$ (after [37]).

\subsection{Iron-Bearing Silicates}

Removal of the iron-bearing silicates from iron ores is challenging because of the presence of both metallic cations and $\mathrm{Si}$ in the crystal lattice of these iron-bearing silicates. These cations and $\mathrm{Si}$ sites may have different affinities with reagents present in the flotation system. Manser [115] categorized the silicates into four groups by structure: orthosilicates, pyroxene, amphiboles, and framework silicates. It was reported that the orthosilicates float well with anionic collectors; pyroxenes float with this collector in some cases, but there is no flotation of amphiboles or framework silicates; and the flotation properties of silicates with cationic collectors are reversed, with orthosilicates and pyroxenes having less floatability than the amphiboles and framework silicates (see Table 4) [115]. 
Table 4. Floatability of different silicates by structure in the presence of cationic and anionic collector (after [115]).

\begin{tabular}{ccccc}
\hline \multirow{2}{*}{ Collector Type } & \multicolumn{4}{c}{ Silicate Class } \\
\cline { 2 - 5 } & Ortho- & Pyroxene & Amphibole & Framework- \\
\hline Anionic & Good & Poor & Nil & Nil \\
Cationic & \multicolumn{2}{c}{$\begin{array}{c}\text { Mediocre } \\
\text { (sensitive to } \mathrm{pH})\end{array}$} & $\begin{array}{c}\text { Good } \\
\text { (not sensitive to pH) }\end{array}$ \\
\hline
\end{tabular}

A group of typical iron-bearing silicates in iron ores is amphibole, with general chemical composition $\mathrm{NaCa}_{2}(\mathrm{Mg}, \mathrm{Fe}, \mathrm{Al})_{5}\left(\mathrm{Al}, \mathrm{Si}_{8} \mathrm{O}_{22}(\mathrm{OH})_{2}\right.$ (the proportions of $\mathrm{Na}, \mathrm{Ca}, \mathrm{Fe}$, and $\mathrm{Mg}$ substitute for one another in the crystal structure). Amphiboles have been investigated through flotation to evaluate the feasibility to separate them from iron oxides [13]. In what follows, we will discuss the flotation behavior of iron-bearing silicates mainly using amphiboles as an example.

Amphiboles can be removed by the use of mixture of amine collectors or an amine collector plus alcoholic surfactants. Note that there is a relatively large uncertainty for the IEP of amphiboles. Severov, et al. [23] noted that the IEP of amphiboles is related to a substitution of $\mathrm{Al}^{3+}$ for $\mathrm{Si}^{4+}$ as well as distribution of $\mathrm{Mg}^{2+}$ in the crystal structure. The cations of $\mathrm{Na}, \mathrm{Ca}, \mathrm{Fe}$, and $\mathrm{Mg}$ can also substitute for one another in the crystal structure. Filippov, et al. [13] reported that amphiboles could achieve a collector adsorption degree similar to quartz over a broad alkaline range of $\mathrm{pH}$, owing to the presence of $\mathrm{Si}$ site at the surface. However, starch adsorption at the surface of amphiboles inhibits their recovery (owing to the presence of Fe site at the surface) when primary monoamines are used as collector of amphiboles. Hence, a denser adsorption layer of collector is needed to render the silicate surface hydrophobic enough to achieve high flotation recovery. It has been discussed in Section 2.3 that the use of a proper mixture of surfactants could result in higher adsorption density and more hydrophobic mineral surface than the use of a single collector. Filippov, et al. [13] found that the mixtures of ether diamine (1,3-Propanediamine of chain lengths $10 \mathrm{C}$ ) with primary monoamine (DDA) or with alcohols (C13-rich) could render the surface of an amphibole hydrophobic, even in the presence of starch, resulting in effective flotation of the silicates with high quality magnetite concentrates $\left(\mathrm{SiO}_{2}\right.$ content $<$ $1.0 \%$ and iron content up to $70.3 \%$ ). There is little information available about the reverse flotation of iron-bearing silicates using anionic collectors. Note, however, that anionic collectors have been used in direct flotation to separate iron oxides from iron-bearing silicates. For example, Mei, et al. [116] achieved flotation separation of aegirine $\left(\mathrm{NaFe}_{2} \mathrm{SiO}_{6}\right)$ from hematite with ammonium hexafluorosilicate $\left(\left(\mathrm{NH}_{4}\right)_{2} \mathrm{SiF}_{6}\right)$ as depressant for aegirine and $\mathrm{NaOl}$ as collector for hematite at $\mathrm{pH} 4-5$. They proposed that the depressant ions $\mathrm{SiF}_{6}{ }^{2-}$ interact with aegirine surface via chemisorption.

\section{Recommendation for Future Work}

Flotation will remain a key process solution for the beneficiation of iron ores in the fine or ultrafine size fractions in the foreseeable future. From the aspect of the collector-mineral interactions, more work needs to be done in water chemistry and reagent development. Water chemistry studies should consider the effects of the quality of recycled water in flotation performance. There can be soluble salts with polyvalent metal cations, residual collector, or depressant contained in the recycled water. A better understanding of the interactions between various minerals and new collectors and their mixture is needed. With the rapid depletion of easy-to-process iron ores, there is a pressing need to develop novel solutions to the flotation of iron ores containing multiple gangues. The gangue minerals may exhibit similar surface properties to iron oxides. Thus, it is necessary to develop a more selective depressant for an efficient separation. In addition, different gangues may preferentially interact with different collectors. It is likely that mixed collectors could exhibit better adaptability to the presence of various gangue minerals and remove the gangues more effectively than single-collector schemes. 


\section{Conclusions}

Reverse cationic and anionic flotation routes are currently used in the iron ore beneficiation industry. Anionic collectors such as fatty acids adsorb at the mineral surface via chemisorption. Cationic collectors such as amines adsorb at the mineral surface via electrostatic interaction. For both cationic and anionic collectors, only a certain type of species can interact with quartz. Hence, the $\mathrm{pH}$ needs to be carefully controlled, at which the desired collector species reaches its maximum concentration. For the advance of collector development, modifying the molecular structure of collectors to improve their activity and selectivity has been an on-going subject. Water chemistry needs to be closely monitored and controlled. In general, the presence of multivalent cations and anions in high concentration can impose a detrimental effect on quartz flotation by adsorbing on the quartz surface and resisting the adsorption of collectors.

The mixture of surfactants has been attracting increasing attention. Anionic surfactant ions can co-adsorb specifically with cations as ion pairs at the non-charged sites of gangue mineral through van der Waals interaction; the presence of nonionic surfactant also increases the adsorption of cationic collector at the solid surface by reducing the electrostatic repulsion between ionic head groups. Both of these mechanisms can lead to increased adsorption density at the mineral surface and enhanced hydrophobicity of the mineral surface.

There are several other non-quartz gangues commonly present in iron ores. The present work provides a review of the interactions between collectors and the non-quartz gangues. In general, there is no universal collector regime and solution chemistry for the removal of various non-quartz gangues. The selection of collector types should be tailored based on the surface characteristics of the gangues. To process iron ores in the presence of multiple gangues, using a more selective depressant would be necessary for an efficient separation.

Author Contributions: Conceptualization, C.L. and Y.C.; investigation, G.F.; writing-original draft preparation, G.F.; writing-review and editing, L.W.; funding acquisition, C.L. All authors have read and agreed to the published version of the manuscript.

Funding: This work was funded by National Natural Science Foundation of China, grant number 51704263, and China Postdoctoral Science Foundation, grant number 2019M652580.

Acknowledgments: The authors also gratefully acknowledge Yuhua Wang for his fruitful advice on this work.

Conflicts of Interest: The authors declare no conflict of interest.

\section{References}

1. Filippov, L.; Severov, V.; Filippova, I. An overview of the beneficiation of iron ores via reverse cationic flotation. Int. J. Miner. Process. 2014, 127, 62-69. [CrossRef]

2. Bruckard, W.; Smith, L.; Heyes, G. Developments in the physiochemical separation of iron ore. In Iron Ore Processing and Environmental Sustainability; Elsevier Science: Burlington, ON, Canada, 2015; pp. 339-356.

3. Standardization Administration of China. Iron Ore Concentrate, Chinese Standard Full-Text Database; Standardization Administration of China: Beijing, China, 2018.

4. Wang, J.; Lu, S.; Rong, L.; Li, D. Effect of silicon contents on the microstructures and mechanical properties of heat affected zones for 9Cr2WVTa steels. J. Nucl. Mater. 2016, 470, 1-12. [CrossRef]

5. Schrama, F.N.H.; Beunder, E.M.; Berg, B.V.D.; Yang, Y.; Boom, R. Sulphur removal in ironmaking and oxygen steelmaking. Ironmak. Steelmak. 2017, 44, 333-343. [CrossRef]

6. Nunes, A.P.L.; Peres, A.E.C.; De Araujo, A.C.; Valadão, G.E.S. Electrokinetic properties of wavellite and its floatability with cationic and anionic collectors. J. Colloid Interface Sci. 2011, 361, 632-638. [CrossRef] [PubMed]

7. Naoi, H.; Ohgami, M.; Liu, X.; Fujita, T. Effects of aluminum content on the mechanical properties of a 9Cr-0.5Mo-1.8W steel. Met. Mater. Trans. A 1997, 28, 1195-1203. [CrossRef]

8. Suhasini, R.; Mallick, A.K.; Vasumathi, N.; Kumar, T.; Rao, S.; Prabhakar, S.; Raju, G.B.; Kumar, S. Evaluation of Flotation Collectors in Developing Zero Waste Technology for Processing Iron Ore Tailings. Int. J. Eng. Res. 2015, 4, 604-608. [CrossRef] 
9. Araújo, A.; Viana, P.R.; Peres, A.E.C. Reagents in iron ores flotation. Miner. Eng. 2005, 18, 219-224. [CrossRef]

10. Rao, K.H.; Forssberg, K. Mixed collector systems in flotation. Int. J. Miner. Process. 1997, 51, 67-79. [CrossRef]

11. Vidyadhar, A.; Rao, K.H.; Ari, V. Adsorption mechanism of mixed cationic/anionic collectors in feldspar-quartz flotation system. J. Colloid Interface Sci. 2007, 306, 195-204. [CrossRef]

12. Wang, L.; Sun, W.; Hu, Y.H.; Xu, L.H. Adsorption mechanism of mixed anionic/cationic collectors in Muscovite-Quartz flotation system. Miner. Eng. 2014, 64, 44-50. [CrossRef]

13. Filippov, L.; Filippova, I.; Severov, V. The use of collectors mixture in the reverse cationic flotation of magnetite ore: The role of Fe-bearing silicates. Miner. Eng. 2010, 23, 91-98. [CrossRef]

14. Quast, K. Literature review on the use of natural products in the flotation of iron oxide ores. Miner. Eng. 2017, 108, 12-24. [CrossRef]

15. Liu, X.H.; Yu, Y.F.; Chen, W.; Yan, X.H. Effect of selective flocculation desliming on flotation of fine grained yuanjiacun iron ore. In Proceedings of the XXVI International Mineral Processing Congress, Delhi, India, 24-28 September 2012; pp. 2980-2992.

16. Luo, X.; Wang, Y.; Wen, S.; Ma, M.; Sun, C.; Yin, W.; Ma, Y. Effect of carbonate minerals on quartz flotation behavior under conditions of reverse anionic flotation of iron ores. Int. J. Miner. Process. 2016, 152, 1-6. [CrossRef]

17. Ma, X.; Marques, M.; Gontijo, C. Comparative studies of reverse cationic/anionic flotation of Vale iron ore. Int. J. Miner. Process. 2011, 100, 179-183. [CrossRef]

18. Nakhaei, F.; Irannajad, M. Reagents types in flotation of iron oxide minerals: A review. Miner. Process. Extr. Met. Rev. 2017, 39, 89-124. [CrossRef]

19. Hu, Y.; Wei, S.; Hao, J.; Miller, J.D.; Fa, K. The anomalous behavior of kaolinite flotation with dodecyl amine collector as explained from crystal structure considerations. Int. J. Miner. Process. 2005, 76, 163-172. [CrossRef]

20. Filippov, L.; Severov, V.; Filippova, I. Mechanism of starch adsorption on Fe-Mg-Al-bearing amphiboles. Int. J. Miner. Process. 2013, 123, 120-128. [CrossRef]

21. Ma, X.; Bruckard, W.; Holmes, R. Effect of collector, $\mathrm{pH}$ and ionic strength on the cationic flotation of kaolinite. Int. J. Miner. Process. 2009, 93, 54-58. [CrossRef]

22. Moudgil, B.M.; Ince, D.E. Flotation separation of apatite from dolomite using dodecylamine and sodium chloride. In Particle Technology and Surface Phenomena in Minerals and Petroleum; Sharma, M.K., Sharma, G.D., Eds.; Springer: Boston, MA, USA, 1991; pp. 191-197.

23. Severov, V.; Filippov, L.; Filippova, I. Relationship between cation distribution with electrochemical and flotation properties of calcic amphiboles. Int. J. Miner. Process. 2016, 147, 18-27. [CrossRef]

24. Ma, M. Froth Flotation of Iron Ores. Int. J. Min. Eng. Miner. Process. 2012, 1, 56-61. [CrossRef]

25. Rao, K.H.; Forssberg, K.S.E. Chemistry of Iron Oxide Flotation. In Froth Flotation-A Century of Innovation; Fuerstenau, M.C., Jameson, G.J., Yoon, R.H., Eds.; Society for Mining, Metallurgy, and Exploration, Inc.: Littleton, CO, USA, 2007; pp. 498-513.

26. Kou, J.; Xu, S.; Sun, T.; Sun, C.; Guo, Y.; Wang, C. A study of sodium oleate adsorption on Ca2+ activated quartz surface using quartz crystal microbalance with dissipation. Int. J. Miner. Process. 2016, 154, 24-34. [CrossRef]

27. Quast, K. The use of zeta potential to investigate the interaction of oleate on hematite. Miner. Eng. 2016, 85, 130-137. [CrossRef]

28. Fuerstenau, D.W.; Cummins, W.F.J. The role of basic aqueous complexes in anionic flotation of quartz. Trans. Am. Inst. Min. Metall. Pet. Eng. 1967, 238, 196-200.

29. Jung, R.F.; James, R.O.; Healy, T.W. Adsorption, precipitation, and electrokinetic processes in the iron oxide (Goethite)-oleic acid-oleate system. J. Colloid Interface Sci. 1987, 118, 463-472. [CrossRef]

30. Liu, A.; Fan, J.-C.; Fan, M.-Q. Quantum chemical calculations and molecular dynamics simulations of amine collector adsorption on quartz (0 0 1) surface in the aqueous solution. Int. J. Miner. Process. 2015, 134, 1-10. [CrossRef]

31. Ozkan, A.; Ucbeyiay, H.; Duzyol, S. Comparison of stages in oil agglomeration process of quartz with sodium oleate in the presence of $\mathrm{Ca}(\mathrm{II})$ and $\mathrm{Mg}$ (II) ions. J. Colloid Interface Sci. 2009, 329, 81-88. [CrossRef]

32. Liu, N.; Wang, Z.; Xiao, J.; Wang, H.; Deng, B.; Zhang, Y.; Chen, C. Novel Selective Depressant of Titanaugite and Implication for Ilmenite Flotation. Minerals 2019, 9, 703. [CrossRef] 
33. Wills, B.A.; Finch, J.A. Wills' Mineral Processing Technology-An Introduction to the Practical Aspects of Ore Treatment and Mineral Recovery, 8th ed.; Elsevier: Amsterdam, The Netherlands, 2016.

34. Somasundaran, P.; Nagarai, D.R. Chemistry and applications of chelating agents in flotation and flocculation. In Reagents in the Minerals Industry; IMM: London, UK, 1984; pp. 209-219.

35. Quast, K. Flotation of hematite using C6-C18 saturated fatty acids. Miner. Eng. 2006, 19, 582-597. [CrossRef]

36. Fuerstenau, D.W.; Jia, R.H. The role of molecular structure of surfactants on the interfacial and flotation behavior of oxide minerals particularly quartz. In Proceedings of the XXIV International Mineral Processing Congress, Beijing, China, 24-28 September 2008.

37. Ogata, Y.; Sugimoto, T.; Inaishi, M. $\alpha$-Chlorination of Long-chain Aliphatic Acids. Bull. Chem. Soc. Jpn. 1979, 52, 255-256. [CrossRef]

38. Zhu, Y.; Luo, B.; Sun, C.; Li, Y.; Han, Y. Influence of bromine modification on collecting property of lauric acid. Miner. Eng. 2015, 79, 24-30. [CrossRef]

39. Luo, B.; Zhu, Y.; Sun, C.; Li, Y.; Han, Y. Flotation and adsorption of a new collector $\alpha$-Bromodecanoic acid on quartz surface. Miner. Eng. 2015, 77, 86-92. [CrossRef]

40. Yang, H.; Tang, Q.; Wang, C.; Zhang, J. Flocculation and flotation response of Rhodococcus erythropolis to pure minerals in hematite ores. Miner. Eng. 2013, 45, 67-72. [CrossRef]

41. Pattanaik, A.; Venugopal, R. Investigation of Adsorption Mechanism of Reagents (Surfactants) System and its Applicability in Iron Ore Flotation-An Overview. Colloid Interface Sci. Comm. 2018, 25, 41-65. [CrossRef]

42. Ofor, O. Effect of Inorganic Ions on Oleate Adsorption at a Nigerian Hematite-Water Interface. J. Colloid Interface Sci. 1996, 180, 323-328. [CrossRef]

43. Tang, M.; Wen, S.M. Effects of Cations/Anions in Recycled Tailing Water on Cationic Reverse Flotation of Iron Oxides. Minerals 2019, 9, 161. [CrossRef]

44. Vidyadhar, A.; Kumari, N.; Bhagat, R.P.; Ari, V. Adsorption Mechanism of Mixed Cationic/Anionic Collectors in Quartz-Hematite Flotation System. Miner. Process. Extr. Met. Rev. 2013, 35, 117-125. [CrossRef]

45. Wang, J.; Somasundaran, P. Adsorption and conformation of carboxymethyl cellulose at solid-liquid interfaces using spectroscopic, AFM and allied techniques. J. Colloid Interface Sci. 2005, 291, 75-83. [CrossRef] [PubMed]

46. Ignatow, A. Cationic Flotation of Siderite. Master's Thesis, Department of Metallurgical Engineering, Mcgill University, Montreal, QC, Canada, November 1975.

47. Shrimali, K.; Jin, J.; Hassas, B.V.; Wang, X.; Miller, J.D. The surface state of hematite and its wetting characteristics. J. Colloid Interface Sci. 2016, 477, 16-24. [CrossRef] [PubMed]

48. Suman, S.K.; Kumar, S. Reverse flotation studies on iron ore slime by the synergistic effect of cationic collectors. Sep. Sci. Technol. 2019, 55, 1-13. [CrossRef]

49. Abaka-Wood, G.B.; Addai-Mensah, J.; Skinner, W. A study of flotation characteristics of monazite, hematite, and quartz using anionic collectors. Int. J. Miner. Process. 2017, 158, 55-62. [CrossRef]

50. Somasundaran, P.; Wang, D.Z. Solution Chemistry: Minerals and Reagents; Elsevier Science: Amsterdam, The Netherlands, 2006.

51. Somasundaran, P.; Fuerstenau, D.W. Mechanisms of Alkyl Sulfonate Adsorption at the Alumina-Water Interface1. J. Phys. Chem. 1966, 70, 90-96. [CrossRef]

52. Zhang, R.; Somasundaran, P. Advances in adsorption of surfactants and their mixtures at solid/solution interfaces. Adv. Colloid Interface Sci. 2006, 123, 213-229. [CrossRef] [PubMed]

53. Huang, Z.; Zhong, H.; Wang, S.; Xia, L.; Zou, W.; Liu, G. Investigations on reverse cationic flotation of iron ore by using a Gemini surfactant: Ethane-1,2-bis(dimethyl-dodecyl-ammonium bromide). Chem. Eng. J. 2014, 257, 218-228. [CrossRef]

54. Fuerstenau, D.W.; Jia, R. The adsorption of alkylpyridinium chlorides and their effect on the interfacial behavior of quartz. Colloids Surf. A Physicochem. Eng. Asp. 2004, 250, 223-231. [CrossRef]

55. Gao, Y.; Du, J.; Gu, T. Hemimicelle formation of cationic surfactants at the silica gel-water interface. J. Chem. Soc. Faraday Trans. 1 Phys. Chem. Condens. Ph. 1987, 83, 2671. [CrossRef]

56. Metzer, A.; Lin, I.J. Effect of dissolved paraffinic gases on the surface tension and critical micelle concentration (cmc) of aqueous solutions of dodecylamine hydrochloride (DACl). J. Phys. Chem. 1971, 75, 3000-3004. [CrossRef]

57. Hoyer, H.W.; Greenfield, A. The critical micelle concentrations of decyl-, dodecyl- and tetradecylamine hydrochloride. J. Phys. Chem. A 1957, 61, 818-819. [CrossRef] 
58. Wang, Y.H.; Ren, J.W. The flotation of quartz from iron minerals with a combined quaternary ammonium salt. Int. J. Miner. Process. 2005, 77, 116-122.

59. Jiang, H.; Liu, G.; Hu, Y.; Xu, L.; Yu, Y.; Xie, Z.; Chen, H. Flotation and adsorption of quaternary ammonium salts collectors on kaolinite of different particle size. Int. J. Min. Sci. Technol. 2013, 23, 249-253. [CrossRef]

60. Montes, S.; Atenas, G.M. Hematite floatability mechanism utilizing tetradecylammonium chloride collector. Miner. Eng. 2005, 18, 1032-1036. [CrossRef]

61. Fuerstenau, D.W.; Modi, H.J. Streaming Potentials of Corundum in Aqueous Organic Electrolyte Solutions. J. Electrochem. Soc. 1959, 106, 336. [CrossRef]

62. Liu, W.; Liu, W.-G.; Zhao, Q.; Peng, X.; Wang, B.; Zhou, S. Investigating the performance of a novel polyamine derivative for separation of quartz and hematite based on theoretical prediction and experiment. Sep. Purif. Technol. 2020, 237, 116370. [CrossRef]

63. Houot, R. Beneficiation of iron ore by flotation-Review of industrial and potential applications. Int. J. Miner. Process. 1983, 10, 183-204. [CrossRef]

64. Papini, R.M.; Brandão, P.R.G.; Peres, A.E.C. Cationic flotation of iron ores: Amine characterization and performance. Min. Met. Explor. 2001, 18, 5-9. [CrossRef]

65. Zana, R. Alkanediyl- $\alpha, w$-bis(dimethylalkylammonium bromide) Surfactants: II. Krafft Temperature and Melting Temperature. J. Colloid Interface Sci. 2002, 252, 259-261. [CrossRef] [PubMed]

66. Weng, X.; Mei, G.; Zhao, T.; Zhu, Y. Utilization of novel ester-containing quaternary ammonium surfactant as cationic collector for iron ore flotation. Sep. Purif. Technol. 2013, 103, 187-194. [CrossRef]

67. Sahoo, H.; Rath, S.S.; Das, B. Use of the ionic liquid-tricaprylmethyl ammonium salicylate (TOMAS) as a flotation collector of quartz. Sep. Purif. Technol. 2014, 136, 66-73. [CrossRef]

68. Sahoo, H.; Rath, S.S.; Jena, S.; Mishra, B.K.; Das, D. Aliquat-336 as a novel collector for quartz flotation. Adv. Powder Technol. 2015, 26, 511-518. [CrossRef]

69. Sahoo, H.; Sinha, N.; Rath, S.S.; Das, B. Ionic liquids as novel quartz collectors: Insights from experiments and theory. Chem. Eng. J. 2015, 273, 46-54. [CrossRef]

70. Krishnan, S.; Iwasaki, I. Pulp dispersion in selective desliming of iron ores. Int. J. Miner. Process. 1984, 12, 1-13. [CrossRef]

71. Somasundaran, P. Cationic depression of amine flotation of quartz. Trans. Metall. Soc. AIME 1974, 256, 64-68.

72. Ahmed, S.M.; van Cleave, A.B. Adsorption and flotation studies with quartz: Part, I. Adsorption of calcium, hydrogen and hydroxyl ions on quartz. Can. J. Chem. Eng. 1965, 43, 23-26. [CrossRef]

73. Tang, M.; Tong, X. The relationship between anion distribution in process water and flotation properties of iron oxides. Miner. Eng. 2020, 154, 106378-106387. [CrossRef]

74. Rama Murthy, R.K.; Mallikajunan, R. Flotation of quartz with soaps of bombax malabarica oil and shark liver oil as collectors. J. Indian Inst. Sci. 1959, 41, 30-35.

75. Lin, X.H.; Lu, P.; Chen, R.H.; Chen, J.; Ma, X.; Lin, B. Preparation and application of a new type of efficient collector-RA-315. Min. Metall. Eng. 1993, 13, 31-35.

76. Wei, Y.H.; Wei, J.X.; Guo, W.D.; Zhou, G.Y. Reverse flotation of iron ore using purified cotton seed fatty acid at ambient temperature. J. Wuhan Univ. Technol. 2015, 37, 36-40.

77. Huang, Z.; Yan, Z.; Gu, T. Mixed adsorption of cationic and anionic surfactants from aqueous solution on silica gel. Colloids Surf. 1989, 36, 353-358. [CrossRef]

78. Filippov, L.O.; Duverger, A.; Filippova, I.V.; Kasaini, H.; Thiry, J. Selective flotation of silicates and Ca-bearing minerals: The role of non-ionic reagent on cationic flotation. Miner. Eng. 2012, 36-38, 314-323. [CrossRef]

79. Vidyadhar, A.; Rao, K.; Chernyshova, I.V.; Pradip; Forssberg, K. Mechanisms of Amine-Quartz Interaction in the Absence and Presence of Alcohols Studied by Spectroscopic Methods. J. Colloid Interface Sci. 2002, 256, 59-72. [CrossRef]

80. Vidyadhar, A.; Kumari, N.; Bhagat, R.; Ari, V. Adsorption mechanism of mixed collector systems on hematite flotation. Miner. Eng. 2012, 26, 102-104. [CrossRef]

81. Leja, J.; Schulman, J.H. Flotation theory: Molecular interaction between frothers and collectors at solid-liquid-air interfaces. Trans. Am. Inst. Min. Metall. Pet. Eng. 1954, 199, 221-228.

82. Sahoo, H.; Rath, S.S.; Rao, D.S.; Mishra, B.K.; Das, D. Role of silica and alumina content in the flotation of iron ores. Int. J. Miner. Process. 2016, 148, 83-91. [CrossRef]

83. Ravishankar Pradip, S.; Khosla, N. Selective flocculation of iron oxide from its synthetic mixtures with clays: A comparison of polyacrylic acid and starch polymers. Int. J. Miner. Process. 1995, 43, 235-247. [CrossRef] 
84. Thella, J.S.; Mukherjee, A.K.; Srikakulapu, N.G. Processing of high alumina iron ore slimes using classification and flotation. Powder Technol. 2012, 217, 418-426. [CrossRef]

85. Kumar, D.; Jain, V.; Rai, B. Can carboxymethyl cellulose be used as a selective flocculant for beneficiating alumina-rich iron ore slimes? A density functional theory and experimental study. Miner. Eng. 2018, 121, 47-54. [CrossRef]

86. Ma, X.; Bruckard, W. The effect of $\mathrm{pH}$ and ionic strength on starch-kaolinite interactions. Int. J. Miner. Process. 2010, 94, 111-114. [CrossRef]

87. Ndlovu, B.; Forbes, E.; Farrokhpay, S.; Becker, M.; Bradshaw, D.; Deglon, D. A preliminary rheological classification of phyllosilicate group minerals. Miner. Eng. 2014, 55, 190-200. [CrossRef]

88. Rodrigues, O.M.S.; Peres, A.E.C.; Martins, A.H.; Pereira, C.A. Kaolinite and hematite flotation separation using etheramine and ammonium quaternary salts. Miner. Eng. 2013, 40, 12-15. [CrossRef]

89. Xu, L.; Hu, Y.; Dong, F.; Gao, Z.; Wu, H.; Wang, Z. Anisotropic adsorption of oleate on diaspore and kaolinite crystals: Implications for their flotation separation. Appl. Surf. Sci. 2014, 321, 331-338. [CrossRef]

90. Li, H.; Franks, G.V. Role of Temperature-Sensitive Polymers in Hydrophobic Aggregation/Flotation of Silicate Minerals. In Proceedings of the XXIV International Mineral Processing Congress, Beijing, China, 24-28 September 2008; pp. 1261-1269.

91. Pereira, A.C.; Papini, R.M. Processes for phosphorus removal from iron ore-A review. Rem Rev. Esc. Minas 2015, 68, 331-335. [CrossRef]

92. Subramanian, S.; Rao, K.H.; Forssberg, K.S.E. Dispersion characteristics of apatite and magnetite fines in the presence of inorganic and organic reagents and its influence on the dephosphorization of magnetite ore. In Beneficiation of Phosphates III_Fundamentals and Technology; Zhang, P., El-Shall, H., Somasundaran, P., Stana, R., Eds.; SME: Littleton, CO, USA, 2002; pp. 21-31.

93. Nunes, A.P.L.; Pinto, C.L.L.; Valadão, G.E.S.; Viana, P.R.D.M. Floatability studies of wavellite and preliminary results on phosphorus removal from a Brazilian iron ore by froth flotation. Miner. Eng. 2012, 39, $206-212$. [CrossRef]

94. Miller, J.D.; Wang, X.M.; Li, M.H. Selective Flotation of Phosphate Minerals with Hydroxamate Collectors. U.S. Patent 6341697 B1, 29 January 2002.

95. Su, F.; Hanumantha Rao, K.; Forssberg, K.S.E.; Samskog, P.O. Dephosphorization of magnetite fines: Part 2: Influence of chemical variables on flotation kinetics. Trans. Inst. Min. Metall. Sec. C Miner. Process. Extr. Metall. 1998, 107, c103-c110.

96. Kou, J.; Tao, D.; Xu, G. Fatty acid collectors for phosphate flotation and their adsorption behavior using QCM-D. Int. J. Miner. Process. 2010, 95, 1-9. [CrossRef]

97. Cao, Q.; Cheng, J.; Wen, S.-M.; Li, C.; Bai, S.; Liu, D. A mixed collector system for phosphate flotation. Miner. Eng. 2015, 78, 114-121. [CrossRef]

98. Horta, D.; de Mello Monte, M.B.; de Salles Leal Filho, E.L. The effect of dissolution kinetics on flotation response of apatite with sodium oleate. Int. J. Miner. Process. 2016, 146, 97-104. [CrossRef]

99. Finkelstein, N.P. Review of interactions in flotation of sparingly soluble calcium minerals with anionic collectors. Trans. Inst. Min. Metall. Sect. C 1989, 988, 157-178.

100. Sis, H.; Chander, S. Adsorption and contact angle of single and binary mixtures of surfactants on apatite. Miner. Eng. 2003, 16, 839-848. [CrossRef]

101. Soto, H.; Iwasaki, I. Flotation of apatite from calcareous ores with primary amines. Mining Met. Explor. 1985, 2, 160-166. [CrossRef]

102. Li, L.X.; Yin, W.Z.; Wang, Y.B.; Tao, S.J. Effect of Siderite on Flotation Separation of Martite and Quartz. J. Northeast. Univ. 2012, 33, 431-434.

103. Yin, W.-Z.; Li, D.; Luo, X.-M.; Yao, J.; Sun, Q.-Y. Effect and mechanism of siderite on reverse flotation of hematite. Int. J. Miner. Met. Mater. 2016, 23, 373-379. [CrossRef]

104. Gu, X.T.; Zhu, Y.M.; Li, Y.J.; Han, Y.X. Selective flotation of siderite and quartz from a carbonate-containing refractory iron ore using a novel amino-acid-based collector. Physicochem. Probl. Miner. Process. 2018, 54, 803-813.

105. Chen, W.; Yu, Y.F.; Feng, Z.L.; Lu, X.S.; Zhao, Q.; Liu, X.Y. Six hundred thousand t/a refractory siderite flash magnetizing roasting complete sets technique and equipment. Met. Mine 2017, 3, 54-58.

106. Laskowski, J.; Nyamekye, G. Colloid chemistry of weak electrolyte collectors: The effect of conditioning on flotation with fatty acids. Int. J. Miner. Process. 1994, 40, 245-256. [CrossRef] 
107. Feng, B.; Luo, X.-P. The solution chemistry of carbonate and implications for pyrite flotation. Miner. Eng. 2013, 53, 181-183. [CrossRef]

108. Forssberg, K.E.; Subrahmanyam, T.; Nilsson, L.K. Influence of grinding method on complex sulphide ore flotation: A pilot plant study. Int. J. Miner. Process. 1993, 38, 157-175. [CrossRef]

109. Shi, Q.; Zhang, G.; Feng, Q.; Deng, H. Effect of solution chemistry on the flotation system of smithsonite and calcite. Int. J. Miner. Process. 2013, 119, 34-39. [CrossRef]

110. Pinto, C.; Peres, A.E.C.; De Araujo, A. The effect of starch, amylose and amylopectin on the depression of oxi-minerals. Miner. Eng. 1992, 5, 469-478. [CrossRef]

111. Sis, H.; Chander, S. Reagents used in the flotation of phosphate ores: A critical review. Miner. Eng. 2003, 16, 577-585. [CrossRef]

112. Quast, K. Use of conditioning time to investigate the mechanisms of interactions of selected fatty acids on hematite. Part 1: Literature survey. Miner. Eng. 2015, 79, 295-300. [CrossRef]

113. Zhang, M. Study on the Floatation Behavior for Donganshan Carbonate-Containing Iron Ore. Ph.D. Thesis, Northeast University, Shenyang, China, May 2009.

114. Abido, A.M. Contribution to concentration of Tin ores by flotation. J. Inst. Eng. India Ser. D 1973, 53, 66-70.

115. Manser, R.M. Handbook of Silicate Flotation; Warren Spring Laboratory: Stevenage, UK, 1975.

116. Mei, G.J.; Rao, P.; Yu, Y.F. Flotation separation of hematite and iron-containing silicate using ammonium hexafluorosilicate depressant. In Proceedings of the XXIV International Mineral Processing Congress, Beijing, China, 24-28 September 2008; pp. 1255-1260.

(C) 2020 by the authors. Licensee MDPI, Basel, Switzerland. This article is an open access article distributed under the terms and conditions of the Creative Commons Attribution (CC BY) license (http://creativecommons.org/licenses/by/4.0/). 